\title{
1 Nucleolar stress in Drosophila neuroblasts, a model for 2 human ribosomopathies
}

3

4

5 Sonu Shrestha Baral, Molly E. Lieux, and Patrick J. DiMario $\bowtie$

6

8

8

9

10

11

12

13

14

15

16

17

18

19

20

21

22

23

24

25

26

27

28

29

30

31

32

33

Rouge, LA 70803 USA.

Email addresses: Sonu Shrestha Baral- $\underline{\text { sshre22@lsu.edu }}$

Molly E. Lieux - mlieux@lsuhsc.edu

Patrick J. DiMario - pdimari@lsu.edu

$\triangle$ To whom correspondence should be addressed (pdimari@lsu.edu)

Running title: Nucleolar stress in neuroblasts

18

(

\section{Summary Statement:} nucleolar stress.

Authors' Affiliation: Department of Biological Sciences, Louisiana State University, Baton

Key words: Nucleolar stress, neuroblasts, Drosophila, Nopp140, ribosomopathy

Nucleolar stress (loss of ribosome production/function) in certain human stem cells or progenitor cells results in disease. In fruit flies, larval Mushroom Body neuroblasts are relatively resilient to 


\section{ABSTRACT}

Different stem cells or progenitor cells display variable threshold requirements for functional ribosomes. For instance, select embryonic neural crest cells or adult bone marrow stem cells, but not others, show lethality due to failures in ribosome biogenesis or function (known as nucleolar stress) in several human ribosomopathies. To determine if various Drosophila neuroblasts display differential sensitivities to nucleolar stress, we used CRISPR-Cas9 to

41 disrupt the Nopp140 gene that encodes two ribosome biogenesis factors (RBFs). Disruption of

42 Nopp140 induced nucleolar stress that arrested larvae in the second instar stage. While the

43 majority of larval neuroblasts arrested development, the Mushroom Body (MB) neuroblasts

44 continued to proliferate as shown by their maintenance of deadpan, a neuroblast-specific

45 transcription factor, and by their continued EdU incorporation. MB neuroblasts in wild type

46 larvae contained more fibrillarin and Nopp140 in their nucleoli as compared to other

47 neuroblasts, indicating that MB neuroblasts stockpile RBFs as they proliferate in late

48 embryogenesis while other neuroblasts normally enter quiescence. A greater abundance of

49 Nopp140 encoded by maternal transcripts in Nopp140-/- MB neuroblasts likely rendered these

50 cells more resilient to nucleolar stress.

51

52

53

54

55

56

57

58

59

60

61

62

63

64

65

66

67 


\section{INTRODUCTION}

The nucleolus is the nuclear sub-compartment responsible for ribosomal subunit biogenesis (Baßler and Hurt, 2019). Functional ribosomes in the cytoplasm of eukaryotic cells consist of the small ribosomal subunit with its 18S ribosomal RNA (rRNA) assembled with 33 ribosomal proteins and the large ribosomal subunit with its 28S, 5.8S, and 5S rRNAs assembled with 47 ribosomal proteins. This assembly is a complex choreography of reactions and interactions that begins with RNA polymerase I (RNA Pol I) as it synthesizes pre-rRNA from tandemly repeated ribosomal DNA (rDNA) genes. The 38S pre-rRNA in Drosophila undergoes endonuclease cleavages to generate 18S, 5.8S+2S, and 28S rRNAs (Long and Dawid, 1980). These rRNAs are chemically modified by box C/D small nucleolar ribonucleoprotein complexes (snoRNPs) (2'-O-methylation) and box H/ACA snoRNPs (pseudouridylation) (Wang et al., 2002; Yang et al., 2000; Bachellerie et al., 2002). Besides endonucleases and snoRNPs, subunit biogenesis requires a myriad of other factors serving as RNP chaperones, RNA helicases, and GTPase release factors (Kressler et al., 2010). The chaperones, often referred to as ribosome biogenesis factors (RBFs), act early in ribosome assembly; they include Nopp140 (Nucleolar and Cajal body phosphoprotein of $140 \mathrm{kDa}$ ) and treacle. While both Nopp140 and treacle are found in vertebrates, only Nopp140 orthologues are expressed in all eukaryotes.

Ribosome biogenesis requires high energy expenditures by the cell; approximately $60 \%$ of total cellular transcription is devoted to rRNA, with some 2000 ribosomes assembled per minute in actively growing yeast cells (Warner 1999; Woolford and Baserga, 2013). Any perturbation in ribosome biogenesis disrupts cell homeostasis; this is now called nucleolar (or ribosome) stress (Golomb et al., 2014; Tsai and Pederson, 2014; Yang et al., 2018). In humans, nucleolar stress due to mutations in ribosome biogenesis factors (RBFs), processing snoRNPs, or the ribosomal proteins themselves results in disease states collectively called ribosomopathies, of which there are several (Narla and Ebert, 2010). While each ribosomopathy has its own distinct phenotypes, and several display tissue-specificity (McCann and Baserga, 2013), there are commonalities among them: the most prevalent dysfunctions include craniofacial abnormalities, other skeletal defects, and bone marrow failures. All ribosomopathies affect only certain stem cells or progenitors despite the mutation being systemic.

One of these ribosomopathies is the Treacher Collins Syndrome (TCS), a congenital

98 birth defect caused by haplo-insufficiency mutations in the TCOF1 gene that encodes treacle

99 (Sakai and Trainor, 2009). A particular set of neural crest cells that normally migrate to and 100 populate pharyngeal arches I and II on day 24-25 human embryogenesis have insufficient 101 functional ribosomes in TCS individuals. This leads to p53-dependent apoptosis (Jones et al., 
2008). Loss of these particular neural crest cells causes the craniofacial defects. A TCS-like phenotype can also result from mutations in genes encoding RNA Pol I and III subunit proteins, POLR1D and POLR1C respectively (Dauwerse et al., 2011; Noack Watt et al., 2016). The question is, why are only certain progenitor cells affected while others remain resilient?

To investigate the underlying mechanism contributing to stem cell or progenitor cell specificity as seen in the human ribosomopathies, we initiated a study of nucleolar stress in

108 Drosophila larval neuroblasts. We wanted to determine if all neuroblast types respond similarly 109 or differentially to nucleolar stress. We typically induce nucleolar stress by depleting Nopp140.

110 Like treacle, metazoan Nopp140 orthologues contain alternating acidic and basic motifs 111 constituting a large central domain of low sequence complexity (Meier, 1996). Treacle and

112 Nopp140 also share similar roles in chaperoning C/D-box snoRNPs to the dense fibrillar 113 component of nucleoli where pre-rRNA is modified by site-specific 2'-O-methylation. Unlike 114 treacle, Nopp140 locates to Cajal bodies; thus Nopp140 may also play a role in snoRNP 115 assembly and transport to nucleoli (Gonzales et al., 2005; Hayano et al., 2003; He et al., 2015).

116 With crucial roles in ribosome biogenesis, Nopp140 depletion in Drosophila induces nucleolar 117 stress such that cell death occurs either by apoptosis in progenitor imaginal disc cells or by 118 autophagy in terminally differentiated polyploid gut cells (James et al., 2013, 2014).

The Drosophila larval brain comprises a diverse set of distinctive neuroblast (NB) lineages generated from a fixed set of founder NBs (Homem and Knoblich, 2012; Hartenstein

121 and Wodarz, 2013). Briefly, there are four major neuroblast types in the Drosophila larval brain;

122 Type I NBs, Type II NBs, Mushroom Body (MB) NBs, and Optic Lobe NBs (Fig. 1A). We

123 hypothesize that upon nucleolar stress caused by the loss of Nopp140, different neuroblast

124 lineages exhibit variable phenotypes ranging from a mild loss of lineage progeny cells to

125 substantial loss of the lineage altogether. Here we show that MB neuroblasts are more resilient

126 to the effects of nucleolar stress compared to other neuroblast types. Hence, different

127 neuroblast lineages respond variably to nucleolar stress which is reminiscent of the neural crest 128 cell-specific effects caused by the loss of treacle in TCS individuals.

\section{MATERIALS AND METHODS}

131 Fly stocks

$132 \quad$ Fly lines used in this study included: $w^{1118}$ (used as a wild type control, Bloomington 133 stock \#3605), the third chromosome balancer stock $w^{*} ; S^{1} / T M 3, P\left\{\right.$ ActGFP\}JMR2, Ser ${ }^{1}$ 134 (referred to as TM3-GFP, Bloomington stock \#4534), $y^{1} M\left\{\right.$ nos-Cas9.P\}ZH-2A $w^{*}$ (referred to as 135 nanos-Cas9, Bloomington stock \#54591 provided by Fillip Port and Simon Bullock, MRC 
Laboratory of Molecular Biology), $w^{*} ; P\{G a w B\} O K 107$ ey $y^{O K 107} / \operatorname{In}(4) c i^{D}, c i^{D}$ pan $^{\text {ciD }} s v^{\text {spa-pol }}$ (referred to as OK107-GAL4, Bloomington stock \#854), w*; P\{wor.GAL4.A\}2; Dr ${ }^{1} / T M 3, P\{U b x-$ lacZ. $\left.w^{+}\right\} T M 3, S b^{1}$ (referred to as worniu-GAL4, Bloomington stock \#56553), $w^{1118}$; $P\{$ GMR37H04-GAL4\}attP2 (referred to as Scabrous (Sca)-GAL4, Bloomington stock \#49969), $w^{1118} ; P\{y[+t 7.7] w[+m C]=G M R 38 F 05-G A L 4\} a t t P 2$ (referred to as Neurotactin (Nrt)-GAL4, Bloomington stock \#49383), $y^{1} w^{*} ; P\left\{w^{+m C}=U A S-m C D 8:: G F P . L\right\} L L 5, P\{U A S-m C D 8:: G F P . L\} 2$

142 (referred to as UAS-mCD8-GFP, Bloomington stock \#5137), KO121 Nopp140 gene deletion line 143 (He et al., 2015), and the UAS-TComC4.2 Nopp140 RNAi line (Cui and DiMario, 2007). Flies 144 were maintained in the laboratory at room temperature $\left(22-24^{\circ} \mathrm{C}\right)$ on standard cornmealmolasses medium. All applicable international, national, and/or institutional guidelines for the care and use of animals were followed.

\section{Homology Directed Insertion of DsRed into Nopp140}

We used CRISPR-Cas9 and homology directed repair to insert the DsRed gene into the second exon of the Nopp140 gene. The CRISPR optimal target finder tool (http://targetfinder.flycrispr.neuro.brown.edu/) provided 271 gRNA target sites, each 20 nt in length excluding the NGG PAM sequence. Among these, six gRNAs had zero off-targets in coding regions of the Drosophila genome. The gRNAs were additionally verified to have no off-

154 targets by the TagScan tool (Genome-wide Tag Scanner;

155 https://ccg.epfl.ch//tagger/tagscan.html), and the Cas-OFFinder tool (Bae et al., 2014). Two

156 gRNA targets, gRNA\#52 (5'GGGCTTTGCCGGTTCTTCCTCGG on the minus strand of

157 Nopp140; with the PAM sequence underlined) and gRNA \#99

158 (5'CAAGTTGGCTCCTGCTAAGAAGG on the plus strand of Nopp140), were chosen and used 159 for CRISPR gene editing. Successful CRISPR-Cas9 cleavage at both gRNA target sites would 160 delete 321 bps from the second exon.

To express these gRNAs, sense and anti-sense oligos that included Bbs/ restriction site 162 overhangs were prepared for both gRNAs by Integrated DNA Technologies (IDT; see Table 1 163 for gRNA sequences). Mixtures of sense and anti-sense oligos for each gRNA were annealed 164 (heated at $95^{\circ} \mathrm{C}$ for $5 \mathrm{~min}$, and then cooled to room temperature over $1 \mathrm{hr}$ in $1 \mathrm{X}$ ligation buffer). 165 The resulting double-strand DNAs were ligated separately into $p C F D 3-d U 6: 3 g R N A$ at the BbsI 166 site. pCFD3-dU6:3gRNA was a gift from Simon Bullock (Addgene plasmid \# 49410;

167 http://n2t.net/addgene:49410; RRID:Addgene_49410; (Port et al., 2014; Ren et al., 2013). The resulting plasmids are referred to as gRNA\#55 and gRNA\#99 (Fig. 2A). 
To mark the disrupted Nopp140 gene, the DsRed gene was inserted at the Cas9mediated deletion site by Homology Directed Repair (HDR). We used the donor plasmid,

$171 p D s R e d-a t t P$ which was a gift from Melissa Harrison, Kate O'Connor-Giles, and Jill Wildonger

172 (University of Wisconsin-Madison) (Addgene plasmid \# 51019; http://n2t.net/addgene:51019;

173 RRID:Addgene_51019; Gratz et al., 2014). We followed general guidelines (Gratz et al., 2014)

174 to insert the homology arms into the multiple cloning sites available on either side of the DsRed

175 gene in pDsRed-attP. The 5' and 3' homology arms from the Nopp140 second exon were

176 prepared by PCR using forward and reverse primers listed in Table 1. These homology arms

177 flank the $321 \mathrm{bp}$ deletion region described in the preceding paragraph (Fig. 2A). We first

178 inserted the 421 bp 3' arm into pDsRed-attP at the Bglll and Xhol sites upstream of the DsRed

179 gene, and then inserted the 500 bp 5' arm at Notl and EcoRI sites downstream of the DsRed

180 gene. The orientation of the homology arms relative to DsRed should insert the DsRed

181 sequence by HDR such that transcription of DsRed is in the opposite direction relative to

182 transcription of the Nopp140 gene (Fig. 2A). The final plasmid is referred to as pDsRed-Donor.

\section{NHEJ disruption of DsRed gene inserted within Nopp140 second exon}

To mutate the DsRed gene within the Nopp140 gene in the J11 DsRed fly line, we used Cas9 endonuclease expressed from the pBS-Hsp70-Cas9 plasmid, a gift from Melissa Harrison,

187 Kate O'Connor-Giles, and Jill Wildonger (Addgene plasmid \# 46294;

188 http://n2t.net/addgene:46294; RRID:Addgene_46294; Gratz et al., 2013). To find gRNA target sites within the DsRed gene, we again used the CRISPR optimal target finder tool which yielded $38 \mathrm{gRNA}$ target sites that were 18-nt in length. Twelve of the $38 \mathrm{gRNA}$ targets had no matches to the Drosophila genome. Among the twelve gRNA targets, we chose gRNA\#2

192 (5'GCTGAAGGTGACCAAGGGCGG on the plus strand of DsRed) and gRNA\#3

193 (5'GCTCCCACTTGAAGCCCTEGG on the minus strand of DsRed). Sense and anti-sense 194 oligos for each gRNA target site were prepared by IDT (see Table 1 for sequences). Each 195 double stranded DNA encoding the respective gRNAs was separately ligated into the $p C F D 3-$ $196 d U 6: 3 g R N A$ plasmid at the Bbs/ restriction site following the same procedures described above 197 for the preparation of $g R N A \# 52$ and $g R N A \# 99$ plasmids. The resulting plasmids for DsRed 198 gene mutagenesis are gRNA\#2 and gRNA\#3.

\section{Drosophila embryo injections}

All plasmids used for embryo injections were extracted from transformed $E$. coli cells using a plasmid Midiprep kit from ThermoFisher Scientific. To disrupt the Nopp140 gene, the 
plasmid injection mixture contained $15 \mathrm{ng} / \mu \mathrm{L}$ of $g R N A \# 52,15 \mathrm{ng} / \mu \mathrm{L}$ of $g R N A \# 99$, and 230 $\mathrm{ng} / \mu \mathrm{L}$ of $p D s R e d-D o n o r$. The mixture was injected into homozygous nanos-Cas9 transgenic embryos. To disrupt the DsRed gene, the CRISPR injection mixture contained $75 \mathrm{ng} / \mu \mathrm{L}$ of gRNA\#2, $75 \mathrm{ng} / \mu \mathrm{L}$ of $g R N A \# 3$, and $350 \mathrm{ng} / \mu \mathrm{L}$ of $p B S-H s p 70-C a s 9$. This mixture was injected into J11 DsRed/TM3-GFP embryos. All injections were performed by GenetiVision Corporation (Houston, TX).

\section{PCR verification of Homology Directed Cas9-mediated donor sequence insertion}

Approximately 30 healthy well-fed adults were homogenized in $100 \mathrm{mM}$ Tris- $\mathrm{HCl}(\mathrm{pH}$ 7.5), $100 \mathrm{mM}$ EDTA, $100 \mathrm{mM} \mathrm{NaCl}$, and $0.5 \%$ SDS, followed by $30 \mathrm{~min}$ incubation at $70^{\circ} \mathrm{C}$.

213 Genomic DNA was precipitated in a 1:2 ratio of $5 \mathrm{M} \mathrm{KOAC} \mathrm{:} 6 \mathrm{M} \mathrm{LiCl}$ on ice for 10 min, followed

214 by phenol-chloroform purification and ethanol precipitation. PCR reactions contained 20-70 ng

215 of genomic DNA, $0.40 \mu \mathrm{M}$ of each primer, $0.20 \mathrm{mM}$ of each dNTP, $0.50 \mathrm{mM}$ of $\mathrm{MgCl}_{2}, 1 \mathrm{X}$

216 Phusion GC Buffer, and 0.40 unit of Phusion high-fidelity DNA polymerase (M0530S, New

217 England BioLabs). Amplification was performed in a BIO-RAD C1000 Thermal Cycler (cycling

218 conditions: 32 cycles of denaturation for $30 \mathrm{sec}$ at $95^{\circ} \mathrm{C}$, annealing for $30 \mathrm{sec}$ at $62^{\circ} \mathrm{C}$, and

219 elongation at $72^{\circ} \mathrm{C}$ for $1 \mathrm{~min} 20 \mathrm{sec}$ ). Primers used for PCR verification were DsRed-Reverse

220 and Nopp140-Exon2-1556. Their sequences are provided in Table 1.

\section{Sequence analyses}

PCR products were extracted from agarose gels using phenol-chloroform, ethanol

224 precipitated, and then sequenced using a BigDye Terminator Cycle Sequencing kit v.3.1 and an 225 ABI 3130XL Genetic Analyzer (Applied Biosystems). Sequencing primers are indicated

226 wherever the sequence reads are provided. Sequences were analyzed and aligned using CLC

227 Sequence Viewer (QIAGEN Bioinformatics).

\section{RT-PCR analysis}

230 Larvae at day 1-2 after larval hatching (ALH) or day 5-7 ALH were collected from well-

231 yeasted grape juice plates, placed into an Eppendorf tube, and rinsed with distilled water to

232 remove yeast and other debris. Total RNA was extracted from wild-type or Nopp140-/- larvae

233 using TRIzol (Invitrogen) according to the manufacturer's recommendations. First-strand cDNA

234 synthesis was performed using M-MuLV Reverse Transcriptase (NEB M0253S) according to

235 manufacturer's recommendations with either oligo(dT) primers or gene-specific reverse primers 
236 (same as the reverse primers used in PCR). Oligo(dT) primers were used to synthesize the first-

237 strand cDNA of Hsp26, RpL32, and Actin5C. Gene-specific reverse primers were used for the

238 ETS and ITS2 regions of pre-ribosomal RNA. Specific forward and reverse PCR primers are

239 described in Table 1.

\section{Immunostaining and fluorescence microscopy}

Larval brains and other tissues were dissected directly into fixation Buffer $\mathrm{B}, \mathrm{pH}$ 7.0-7.2

243 (16.7 mM KH $2 \mathrm{PO}_{4} / \mathrm{K}_{2} \mathrm{HPO}_{4}, 75 \mathrm{mM} \mathrm{KCl}, 25 \mathrm{mM} \mathrm{NaCl}, 3.3 \mathrm{mM} \mathrm{MgCl}$ ) (de Cuevas and

244 Spradling, 1998) with 2\% paraformaldehyde (from a freshly prepared 10\% stock). Tissues were

245 fixed for 30-35 min total starting from the point when the dissection commenced. All washings

246 were done with PBS with 0.1\% TX-100 detergent. The blocking solution was 3\% BSA prepared

247 in PBS with $0.1 \%$ TX-100 which was also used for preparing dilutions of primary and secondary

248 antibodies. In all cases, tissues were incubated in the primary antibody overnight at $4^{\circ} \mathrm{C}$ on a

249 shaker, and in the secondary antibody for $4 \mathrm{hr}$ at $4^{\circ} \mathrm{C}$ on a shaker. Primary antibodies included

250 the polyclonal guinea pig anti-Nopp140-RGG (Cui and DiMario, 2007) used at 1:100, a rat

251 monoclonal anti-Deadpan (abcam, 195173, stock $1 \mathrm{mg} / \mathrm{ml}$ ) used at 1:250, the mouse

252 monoclonal anti-fibrillarin mAb 72B9 (Reimer et al., 1987; hybridoma supernatant used without

253 dilution), the mouse monoclonal anti-prospero (deposited at the DSHB by C.Q. Doe; DSHB

254 Hybridoma Product: Prospero MR1A) used at 1:50, and the mouse monoclonal anti-discs large

255 (dlg) (deposited at the DSHB by C. Goodman; DSHB Hybridoma Product: 4F3 anti-discs large)

256 used at 1:30. Secondary antibodies included the Alexa Fluor 546 conjugated goat anti-rat (A-

257 11081, ThermoFisher Scientific) used at 1:1000, the Alexa Fluor 594 conjugated goat anti-

258 guinea pig (A-11073, ThermoFisher Scientific) used at 1:500, and the Dylight 488 conjugated

259 goat anti-mouse (35503, ThermoFisher Scientific) used at 1:500. Tissues were counter-stained

260 with 4',6-diamino-2-phenylindole (DAPI, Polysciences) at $1 \mu \mathrm{g} / \mathrm{mL}$. To image the tissues, we 261 used either a conventional fluorescence microscope, a Zeiss Axioskop equipped with a SPOT

262 RTSE digital camera, or a Leica SP8 Confocal Microscope equipped with the White Light Laser 263 system in the Shared Instrumentation Facility (SIF) at Louisiana State University.

\section{EdU labeling}

266 For 5-ethynyl-2-deoxyuridine (EdU) labeling, larval brains were dissected in PBS

267 (without any detergent or azide), and within 5 min of dissection, the brains were incubated with

$26820 \mu \mathrm{M} \mathrm{EdU}$ in PBS for $30 \mathrm{~min}$ or $2 \mathrm{hr}$ at room temperature. The tissues were then fixed in Buffer

269 B with $2 \%$ paraformaldehyde (described above) for $30 \mathrm{~min}$ at room temperature. EdU 
270 incorporated into S-phase cells was detected by a Click-iT Alexa Fluor 488 EdU imaging kit

271 (Invitrogen) according to the manufacturer's recommendation. EdU was also detected by Alexa

272 Fluor 594-Azide (Product No.1295, AF 594 Azide from Click Chemistry Tools) used with the

273 reagents provided by Invitrogen Click-iT EdU imaging kit. Following EdU labeling, the larval

274 brains were immunostained with antibodies followed by DAPI counterstaining.

\section{Determination of nuclear area}

The 2D confocal images of the Nopp140-/- and wild-type larval brains at day 2-3 ALH

278 were analyzed using Fiji software. After setting scale for each image, the free hand selection

279 tool was used to draw outlines of each nucleus, and the nuclear area was subsequently

280 recorded. Deadpan-stained larval brains were used to determine the nuclear area of

281 neuroblasts. Neuronal nuclear area was obtained from the DAPI-stained larval brains. The

282 nuclear areas were plotted into a box-scatter plot using Microsoft Excel, and a Student's t-test

283 (one-tailed) was performed on the data.

\section{RESULTS}

\section{CRISPR for homology directed repair (HDR) to disrupt the Nopp140 gene}

We used CRISPR-Cas9 to delete a target sequence of 321 bps from the second exon of the Nopp140 gene. A cocktail of two gRNA plasmids and the DsRed-Donor plasmid was injected into embryos homozygous for the nanos::Cas9 transgene (Fig. 2A). The gRNAs directed the Cas9-mediated deletion, and HDR inserted the DsRed gene across the deletion (Fig. 2A). DsRed then served as a selectable marker for the disrupted Nopp140 gene; it was expressed from the 3xP3 eye promoter which is normally active in the entire embryonic and larval brain, Bolwig's organ, hind gut, anal pads, and adult eyes. We recovered seven independent Nopp140 disruption lines (J11, J47, J54, J60, K13, M6, M20) using the red fluorescence eye phenotype. Each of the seven Nopp140 disrupted chromosomes was maintained over the TM3-GFP balancer chromosome which carries a wild type copy of Nopp140. The DsRed insertion was verified by genomic PCRs (Fig. 2B). The expected 1836 bp

298 PCR product was amplified in all seven Nopp140 insertion alleles, with $w^{1118}$ acting as a wild 299 type negative control (Fig. 2A,B). Among the seven lines initially recovered, J11 ${ }^{\text {DsRed }} /$ TM3-GFP $^{2}$

300 was backcrossed with the $S b^{1} / T M 3-G F P$ fly line for at least six generations to eliminate possible 301 off-target mutations in the $J 11^{\text {DsRed }}$ line.

302 The GFP reporter gene on the TM3 balancer chromosome is expressed in a small 303 cluster of larval midgut cells that are easily identifiable. Therefore, with inter se crosses of 
$J 11^{\text {DsRed }} /$ TM3-GFP stock flies, we hand-selected larvae that were homozygous for $J 11^{\text {DsRed }}$, but selected against sibling larvae heterozygous for $J 11^{\text {DsRed }} / T M 3$-GFP with prominent GFP signals in their midgut.

To conduct multi-channel immunofluorescence of the Drosophila brain, we again used CRISPR-Cas9 but now with Non-Homologous End Joining (NHEJ) to disrupt the DsRed gene inserted in the $J 11^{\text {DsRed }}$ allele. A cocktail of two gRNA plasmids and the $p B S-H s p 70$-Cas9 vector injected into $J 11^{\text {DsRed }} / T M 3$ embryos produced several independent fly lines with mutations in DsRed (Supplementary Fig. S1). We sequenced the second exon region in two of these lines, $A 5$ and $A 7$, and verified that each had a short deletion at the gRNA\#3 target site within the

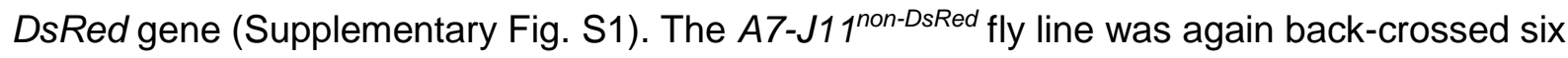
times to deplete any possible off-site targets. Either the original $J 11^{\text {DsRed }}$ fly line or its derived A7-J11 $1^{\text {non-DsRed }}$ line was used for the experiments described below.

We next performed RT-PCR analyses to test if the disrupted Nopp140 gene was transcribed in homozygous A7-J11 1 non-DsRed larvae (day 1-2 ALH) (Fig. 2C). The reverse primer referred to as $p D s R e d$ in Fig. $2 \mathrm{C}$ annealed to the $p D s R e d$-attP plasmid sequence a few base pairs downstream of the junction between the Nopp140 second exon and the DsRed donor sequence. No transcripts containing DsRed-att sequences were detected in the total RNA samples prepared from homozygous A7-J1 1 $1^{\text {non-DsRed }}$ larvae 1-2 day, similar to the $w^{1118}$ sample

322 that served as a negative control (Fig. 2C, but see below for a positive control). Nonsense-

323 mediated decay (NMD) would likely degrade Nopp140 pre-mRNAs transcribed from the

324 disrupted gene as they would likely contain premature stop codons within the $p D s R e d$-att sequences, or these pre-mRNAs may be improperly/incompletely spliced (Garneau et al., 2007). This lack of RT-PCR products eliminates the likelihood of a dominant-negative effect due to the production of truncated Nopp140 proteins encoded by the disrupted Nopp140 gene. In

328 summary, hand-selected larvae homozygous for the Nopp140 J11 ${ }^{\text {non-DsRed }}$ allele provide a null genotype (Nopp140-/-) systemic throughout the larvae.

We next determined if there were maternal wild type Nopp140 transcripts present in the

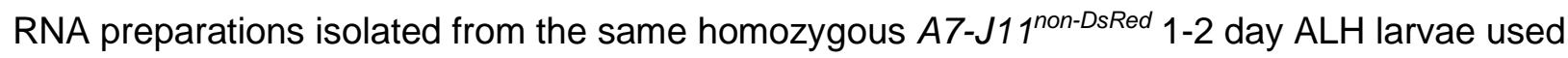

332 for the RT-PCRs described in the preceding section. We performed these second RT reactions

333 using a reverse primer (Exon2, blue in Fig. 2C) that anneals to the Nopp140 second exon a few 334 base pairs upstream of the junction between the Nopp140 second exon and the DsRed donor 335 sequence. Since Nopp140 transcripts harboring DsRed sequences were undetectable in these 336 larvae, first strand cDNAs primed with Exon2 should indicate the presence of maternal Nopp140 337 transcripts in homozygous $J 11^{\text {DsRed }}$ larvae, and thus serve as a positive control for the initial RT- 
PCRs that showed an absence of DsRed-att-containing transcripts. These second RT-PCRs showed that maternal Nopp140 transcripts were indeed present in the Nopp140-/- larvae at day 1-2 ALH. The abundance of maternal Nopp140 transcripts in the Nopp140-/- larvae was about half that seen in wild type larvae, suggesting that both maternal and zygotic Nopp 140 transcript pools exist in early wild type larvae (Fig. 2C).

As additional controls (Fig. 2D), RT-PCR analyses of the External Transcribed Spacer

344 (ETS) and the Internal Transcribed Spacer 2 (ITS2) sequences within pre-rRNA showed that

345 their levels were unaffected in homozygous $J 11^{\text {DsRed }}$ larvae at day 1-2 ALH and at day 5-7 ALH.

346 This indicates that loss of Nopp140 had no effect on rDNA transcription, which agreed with our

347 earlier observations with a pBac-generated Nopp140 $0^{K O 121}$ deletion line (He et al., 2015).

348 Furthermore, Hsp26 transcript levels were upregulated in homozygous $J 11^{\text {DsRed }}$ larvae at both

349 day 1-2 and day 5-7 ALH, whereas the wild-type larvae had almost undetectable levels of

$350 H s p 26$ transcript (Fig. 2D). Overexpression of Hsp26 in homozygous J11 $1^{\text {DsRed }}$ larvae as early as

351 day $1 \mathrm{ALH}$ indicated a cellular stress response due to the effects of Nopp140 loss (e.g., Wang

352 et al., 2004). As final controls, we accessed RpL32 and Actin5C transcript levels: while RpL32

353 transcript levels remained unchanged between the wild-type and homozygous J11 ${ }^{\text {DsRed }}$ samples

354 and between biological replicates, Actin5C transcript levels fluctuated slightly within the samples

355 and between biological replicates for reasons that remain uncertain.

Maternal Nopp140 protein is reduced in early J11 Nopp140-/- larval brains

Since the RT-PCR analyses showed that maternal Nopp140 transcripts persisted in the homozygous $J 11^{\text {DsRed }}$ larvae at day 1-2 ALH, we wanted to test if the Nopp140 protein could be detected in their brain and gut tissues as well. To do this, we immunostained homozygous $A 7-$ $J 11^{\text {non-DsRed }}$ larvae and wild-type larvae with an antibody directed against Nopp140-RGG, one of the two Nopp140 isoforms in Drosophila. This antibody was raised against a synthetic peptide, the sequence of which is unique to the carboxyl tail region of Nopp140-RGG (see Cui and DiMario, 2007). An antibody directed against the carboxyl terminus of the other isoform, Nopp140-True, has proven much weaker, and was not used here. At day 1-2 ALH, the antiNopp140-RGG antibody labeled nucleoli in homozygous $J 11^{\text {non-DsRed }}$ larval brain and midgut, but at lower levels compared to the same wild type tissues (Fig. 3, panels a-d for brain, e-h for gut

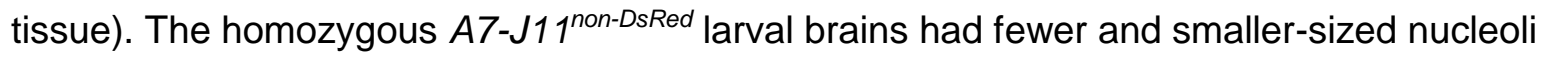

370 large-sized nucleoli per brain lobe were routinely detected in the anterior of wild-type larval

371 brains, and we speculated these were the Mushroom Body (MB) neuroblasts that do not 
372 undergo quiescence, but continue to divide throughout the embryo-to-larva transition (arrow in

373 Fig. 3a). However, we did not observe this preferential labeling in homozygous A7-J11 ${ }^{\text {non-DsRed }}$

374 brains. By day 4-5 ALH, nucleolar labeling by anti-Nopp140-RGG was noticeably reduced in

375 homozygous A7-J11 ${ }^{\text {non-DsRed }}$ larval brains and gut tissues as compared to the wild type tissues

376 (Fig. 3, panels i-I for brain, m-p for midgut). These results indicated that at least the Nopp140-

377 RGG isoform encoded presumably by maternal transcripts persisted in the first two days of

378 homozygous A7-J11 ${ }^{\text {non-DsRed }}$ larval development, but then diminished in most cells as these

379 larvae aged.

\section{Embryonic and larval survivability with complete or partial elimination of Nopp140}

The Nopp140 disruption lines were maintained using the third chromosome balancer, TM3, which carries a wild type Nopp140 gene. Embryos homozygous for TM3 are non-viable, hence inter se crosses within the J11 ${ }^{\text {DsRed }} / T M 3$ fly stock should produce $50 \%$ Nopp $140^{\text {DsRed }} / T M 3$ larvae and $25 \%$ homozygous $\mathrm{J} 11^{\text {DsRed }}$ larvae (the number of hatched larvae $\div$ total number of eggs collected). However, if the disrupted Nopp140 gene causes embryonic lethality, we would expect frequencies less than $50 \%$ and $25 \%$, respectively. We found that only $20.8 \%$ of total eggs developed into larvae that were $J 11^{\text {DsRed }} / T M 3$ versus the expected $50 \%$ (Fig. 4A), and only $7.1 \%$ of the total eggs developed into larvae that were homozygous for $J 11^{\text {DsRed }}$ versus the expected $25 \%$ (Fig. 4A). These data indicated that loss of Nopp140 leads to partial embryonic lethality not only for the homozygous $J 11^{\text {DsRed }}$ genotype, but more interestingly for the heterozygous $\mathrm{J} 11^{\text {DsRed }} / T M 3$ genotype. The observation indicated for the first time that the Nopp140-/+ genotype exhibits haplo-insufficiency in Drosophila, similar to the Tcof1-/+ genotype in the human Treacher Collins Syndrome.

We earlier described growth arrest and lethality in second instar larvae that were homozygous for our original pBac-mediated Nopp $140^{K O 121}$ deletion (He et al., 2015). Because of the particular pBac elements available at the time, we had to delete the 3 ' end of the downstream gene, P5CDh1 (He and DiMario, 2011), and this constantly forced us to control for the carboxyl truncation in the protein product when assessing the loss of Nopp140. Here, we assessed survivability of larvae homozygous for $J 11^{\text {DsRed }}$. Similar to our earlier findings (He et

402 the pupal stage normally begins) (Fig. 4B). The remaining 50\% remained as second instar 403 larvae; they failed to grow or molt. The number of surviving homozygous $J 11^{\text {DsRed }}$ larvae 404 dwindled over time, but interestingly, some lingered up to day 24 (Fig. 4B). 
We also depleted Nopp140 using the UAS-GAL4 system to express siRNAs. In the past we showed that daughterless::GAL4>UAS::TComC4.2 depleted $~ 70 \%$ of the Nopp 140 transcripts (Cui and DiMario, 2007). Using the neuroblast-specific worniu::GAL4 driver (worniuGAL4>UAS::TComC4.2), we found embryonic survivability was $\sim 46 \%$, while the wild type embryo survival rate was $\sim 86 \%$ (Fig. $4 \mathrm{C}$ ). Interestingly, the surviving worniu::GAL4>UAS::TCOmC4.2 larvae developed into viable and fertile adults. While the worniu promoter is active in all embryonic and larval neuroblasts, its peak expression is in 6-12 $\mathrm{hr}$ embryos, perhaps explaining the survivability of nearly half the worniu::GAL4>UAS::TComC4 embryos beyond this embryonic stage.

\section{Brain hypoplasia upon nucleolar stress}

We found that larval brain development was severely impaired upon loss of Nopp140 either by gene disruption (i.e., homozygous $J 11^{\text {DsRed }}$ ) or by neuron-specific RNAi depletion. During the early larval stage (day 1-2 ALH), homozygous $J 11^{\text {DsRed }}$ brains were morphologically comparable in size to brains from newly hatched wild-type larvae. The mutant's brain continued to grow from day 3-6 ALH, but more slowly compared to wild-type larval brains (Fig. 5A). we saw in our original Nopp140 ${ }^{K O 121}$ deletion (He et al., 2015) (Fig. 5A). Likewise, brain growth was impaired in larvae upon RNAi-mediated depletion of Nopp140 using a pan-neuronal GAL4 driver (Neurotactin::GAL4>UAS::TComC4.2) (Fig. 5B).

To see where growth was interrupted, we immunostained brains from homozygous $J 11^{\text {DsRed }}$ larvae and wild type larvae at day 2-3 ALH with an antibody against discs large (anti-

427 Dlg). This antibody stains axon bundles (the neuropil), but not the cell body mass which we 428 counter-stained with DAPI. Neuropils within the two central brain lodes were reduced in 429 homozygous $\mathrm{J} 11^{\text {DsRed }}$ brains as compared to wild type brains, but there were no observable 430 physical defects in the ventral nerve cord (VNC) neuropil of homozygous $\mathrm{J1} 1^{\text {DsRed }}$ larvae when 431 compared to wild type larvae. Besides the reduced central brain lobe neuropils, we found the

432 cell body mass of the central brain lobe was also reduced in homozygous $J 11^{\text {DsRed }}$ brains when

433 compared to wild type brains (Fig. 5C).

\section{Reduced neuroblast numbers and proliferation upon nucleolar stress}

437 reduction in NB numbers, a reduction in their proliferative capacity, or both. To assess these 438 possibilities, we first performed a Click-iT EdU labeling assay on living brains. EdU is a 
thymidine analog which is incorporated into genomic DNA during S-phase of the cell cycle, and hence these cells are committed to cell division. The assay used a $2 \mathrm{hr}$ EdU pulse in wild type

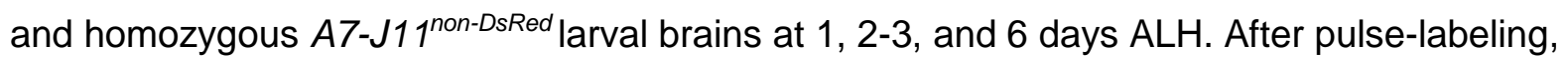

442 brains were fixed with paraformaldehyde, and the EdU residues were fluorescently labeled by

443 Click-iT chemistry. We then immunostained the same brains with anti-Deadpan to visualize the

444 number and distribution of neuroblasts. Deadpan (Dpn) is a neuroblast-specific transcription

445 factor necessary for self-renewal properties.

Anti-Dpn labeling showed that NBs were present in homozygous $J 11^{\text {non-DsRed }}$ larval brains

447 from all age groups, however their numbers were consistently reduced compared to the wild-

448 type brains of the same age (Fig. 6; compare homozygous $J 11^{\text {non-DsRed }}$ panels a, g, and $\mathrm{m}$ with

449 wild-type panels $d$, j, and p). This suggested that fewer neuroblasts in the homozygous $J 11^{\text {non- }}$

450 DsRed larval brains likely contributed to the observed hypoplasia. Strikingly, in homozygous

$451 J 11^{\text {non-DsRed }}$ larvae at day 1 and day 2-3 ALH, we consistently noticed four NBs in each central

452 brain lobe that showed prominent anti-Dpn labeling compared to the surrounding Dpn-stained

453 NBs (Fig. 6; arrows in panels a and g). These four NBs were visible in the wild-type brains as

454 well, but only in brains from day 1 ALH larvae (Fig. 6; arrows in panel d).

EdU labeling displayed NBs and their progeny GMCs that were in S-phase. Overall,

456 homozygous $\mathrm{J1} 1^{\text {non-DsRed }}$ larval brains had fewer EdU-positive cells as compared to the wild-type

457 brains in all three examined age groups (Fig. 6; compare homozygous $J 11^{\text {non-DsRed }}$ panels b, h,

458 and $n$ with wild-type panels $e, k$, and $q$ ). The same subset of the EdU-positive cells in both

459 homozygous $J 11^{\text {non-DsRed }}$ and wild-type brains were identified as NBs by the anti-Dpn nuclear

460 staining. Other than the four NBs that co-labeled with EdU and anti-Dpn in both homozygous

$461 J 11^{\text {non-DsRed }}$ and wild-type larval brains at day $1 \mathrm{ALH}$, there were also fewer EdU-positive GMCs

462 in the homozygous $J 11^{\text {non-DsRed }}$ brains compared to the wild-type brains (Fig. 6; compare

463 Nopp140-/- panels a, b with wild type panels d, e). This suggested a slower rate of NB

464 proliferation in the homozygous $J 11^{\text {non-DsRed }}$ larval brains compared to the wild-type NBs.

465 At day 2-3 ALH, we consistently observed only the four anterior NBs that co-labeled

466 with both EdU and anti-Dpn in homozygous $\mathrm{J} 11^{\text {non-DsRed }}$ brains (Fig. 6, arrows in panels $\mathrm{g}$ and $\mathrm{h}$ ).

467 We predicted that these NBs were the MB NBs based on their location and consistency in

468 number. Wild-type larval brains, however, had more EdU-positive and Dpn-positive cells,

469 suggesting that the majority of NBs had exited quiescence and started to proliferate as expected

470 (Fig. 6, panels j and k). At day $1 \mathrm{ALH}$, we also noticed other EdU-positive cells in the lateral

471 regions of the central brain lobes from both homozygous $J 11^{\text {non-DsRed }}$ and wild-type larvae (Fig.

4726 , arrowheads in panels $b$ and e). These should be the Antennal Lobe (AL) NBs. They were 
occasionally detected in central brain lobes of day 2-3 ALH homozygous $J 11^{\text {non-DsRed }}$ (Fig. 6 , arrowheads in panel $\mathrm{h}$ ).

These observations indicate that upon nucleolar stress, only a subset of neuroblasts and GMCs proliferate in homozygous $J 11^{\text {non-DsRed }}$ brains although at a slower rate, and give rise to

477 lineages that are comparatively smaller than those in wild type brains under non-stressed

478 conditions. Indeed, using an antibody against Prospero, a nuclear marker specific for GMCs and

479 their descendent glia and neurons, we found significantly fewer GMC populations in the

480 homozygous $J 11^{\text {non-DsRed }}$ brains than in wild-type brains at day 1-2 and 6-7 ALH (Supplementary

481 Fig. S2). Additionally, we found that the nuclear volumes in the NBs and neurons were

482 noticeably reduced in homozygous $J 11^{\text {non-DsRed }}$ larval brains compared to wild-type larval brains

483 at day 2-3 ALH (Supplemental Fig. S3). Thus, upon nucleolar stress, larval brain hypoplasia

484 resulted from the loss of mostly Type I and II neuroblasts, the reduced size of remaining

485 neuroblasts and neurons, and the inability of these neuroblasts to proliferate.

\section{Mushroom body neuroblasts are resilient to nucleolar stress}

To test if the four anterior EdU-positive NBs were in fact MB NBs, we used a MB lineage-specific GAL4 driver to express a GFP-tagged plasma membrane reporter protein, mCD8-GFP (OK107::GAL4>mCD8::GFP), and again performed a 30 min co-EdU-labeling in brains from both homozygous $J 11^{\text {non-DsRed }}$ and control larvae at day $3 \mathrm{ALH}$ (see the genetic cross scheme in Supplemental Fig .S4). EdU labeling showed many S-phase cells in the wild type larval brains; a subset of these cells located within the mCD8-GFP-positive MB-lineage cell cluster (Fig. 7; panel c). In the homozygous $J 11^{\text {non-DsRed }}$ larval brains at day $3 \mathrm{ALH}$, EdU-positive cells in the anterior region of the CBs were always located within the MB lineage-cell cluster as identified by mCD8-GFP (Fig .7; panel g). This suggested that the four Dpn-positive and EdUpositive NBs that we observed in homozygous $J 11^{\text {non-DsRed }}$ larval brains at day 2-3 ALH (Fig. 6; panel $g$ and $h$ ) were indeed MB NBs. The combined results of Figs. 6 and 7 suggest that the MB NBs are more resilient to nucleolar stress induced by the loss of Nopp140 as compared to other NBs within these brains.

\section{Mushroom body neuroblasts in the Nopp140-/- larval brain retain nucleolar fibrillarin}

Nopp140 is a chaperone for C/D-box snoRNPs that catalyze 2'-O-methylation of prerRNA during ribosome biogenesis. Previous work in our lab showed that the C/D-box snoRNP

505 methyl-transferase, fibrillarin, redistributes to the nucleoplasm upon complete loss of Nopp140 506 in larval tissues homozygous for the Nopp140 ${ }^{K O 121}$ gene deletion. Loss of fibrillarin from the 
507 nucleoli caused a reduction in 2'-O-methylation of pre-rRNA clearly indicating nucleolar

508 dysfunction, even though gross nucleolar morphology and rDNA transcription remained normal

509 (He at al., 2015). Since MB NBs, but not others, continue to divide in Nopp140-/- larval brains at

510 day 2-3 ALH, we predicted that MB NBs might retain fibrillarin within their nucleoli, while other

511 NBs and their lineages redistribute fibrillarin to the nucleoplasm. To test this, we immunostained

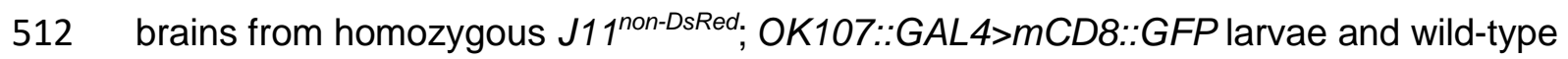

513 OK107::GAL4>mCD8::GFP larvae (see the genetic cross scheme in Supplemental Fig. S4) with

514 anti-fibrillarin at day 3 ALH. While anti-fibrillarin stained nucleoli with minimal nucleoplasmic

515 labeling in the wild-type larval brains (Fig. 8), it labeled the nucleoplasm in the majority of brain

516 cells in homozygous $J 11^{\text {non-DsRed }}$ larval brains, except for a small number of cells located within

517 the MB-lineage as marked by mCD8-GFP labeling; these cells showed clear nucleolar labeling

518 with anti-fibrillarin, even though there was some nucleoplasmic labeling (Fig. 8). This result

519 indicates that the MB-lineage cells, and not others, are able to retain at least some nucleolar

520 fibrillarin, indicating that their nucleoli are partially functional.

\section{A transcriptomics perspective}

With MB NBs apparently retaining fibrillarin, we asked how much Nopp140 and fibrillarin

524 are normally present within wild type MB neuroblasts relative to other neuroblasts. As an initial

525 query, we analyzed the NB-lineage specific transcriptome data set from Yang et al. (2016) who

526 performed a cell-type specific RNA-seq analysis for Drosophila larval neuroblasts (non-selective

527 “all” NBs, MB NBs, AL NBs, and Type II NBs), neurons, and glia. We found the expression

528 levels of four RBFs (Nopp140, fibrillarin, Nop56, and Nop60B) were higher in the MB NBs

529 compared to the AL NBs and Type II NBs (Fig. 9A). We also checked the expression levels of

530 the four Drosophila Nucleostemin orthologues (NS1 - NS4) (Kaplan et al., 2008; Rosby et al.,

531 2009; Hartl et al., 2013; Wang and DiMario, 2017). Mammalian nucleostemin (NS) is a nucleolar

532 GTP-binding protein originally described in embryonic and neuronal stem cells and in certain

533 cancer cells that can regulate both ribosome production and cell cycle progression (Tsai, 2011).

534 We found NS1, NS2, and NS4, but not NS3 expressed at higher levels in the neuroblasts than

535 in neurons (Fig. 9B). As controls, we checked the expression levels of Deadpan which encodes

536 a NB-specific transcription factor, Prospero which encodes a NB- and GMC-specific

537 transcription factor, and Elav which encodes a Drosophila neuron-specific protein. As expected,

538 Deadpan and Prospero expression levels were higher in NBs compared to neurons, and Elav

539 expression was higher in neurons compared to NBs (Fig. 9C).

$540 \quad$ To inquire if differences exist in the expression levels for genes encoding ribosomal 
541 proteins in different NB lineages, we again analyzed the transcriptomic data set of Yang et al.

542 (2016). Out of 92 genes encoding ribosomal proteins (recall that $\sim 80$ different proteins

543 constitute an intact ribosome), 47 genes were preferentially expressed in MB NBs compared to

544 AL NBs, Type II NBs, and neurons (Supplemental Fig. S5). Noticeably, RpL41 had the highest

545 expression levels among all ribosomal protein genes in all brain cell types examined, but $R p L 41$

546 transcripts levels were significantly higher in the MB NBs (indicated by an asterisk in

547 Supplemental Fig. S5). Enhanced expression of RpL41 and the other 46 genes in MB NBs

548 suggests that their ribosomes may be different from those in other NB lineages.

DISCUSSION

A wealth of knowledge exists for Drosophila neurogenesis making it possible to analyze

552 developing brains at the level of individual neuroblast lineages (Birkholz et al., 2015; Egger et

553 al., 2008; Hartenstein and Wodarz, 2013; Homem and Knoblich, 2012; Urbach and Technau,

554 2003). We asked if Type I and II neuroblasts, Mushroom Body (MB) neuroblasts, Optic Lobe

555 neuroblasts, and Antennal Lode $(\mathrm{AL})$ neuroblasts are affected variably upon nucleolar stress, as

556 are stem cells and precursor cells in the human ribosomopathies. To induce nucleolar stress,

557 we used CRISPR-Cas9 to disrupt the Nopp140 gene which encodes two isoforms that function

558 as early RBFs. Drosophila larvae homozygous for the Nopp140 disruption allele, J11 ${ }^{\text {non-DsRed, }}$

559 showed smaller brains by day 4 ALH (Fig. 5A). These Nopp140-/- larvae arrested in the second

560 instar stage, and while some lingered to day $24 \mathrm{ALH}$; none of them survived (Fig. 4B).

561 Compared to wild-type brains, Nopp140-/- larval brains at day 2-3 ALH had far fewer

562 proliferating NBs. However, deadpan antibody labeling and EdU labeling of homozygous $\mathrm{J11}^{\text {non- }}$

563 DsRed larvae showed that MB neuroblasts, and in some cases the AL neuroblasts, proliferated

564 through the embryo-to-larva transition and continued to proliferate at day 2-3 ALH as other

565 neuroblast lineages remained arrested (Fig. 6). Hence, MB NBs exhibited resilience to nucleolar

566 stress due to loss of zygotic Nopp140 gene expression.

Ontogenesis of the Mushroom Body Neuroblast Lineages

Insect MBs are central hubs for olfactory sensory input, learning, and memory (Thum

570 and Gerber, 2019). Formation of the MBs begins during embryogenesis during which each MB

571 NB differentially expresses unique combinations of the regulatory genes (Kunz et al., 2012;

572 Yang et al., 2016). As far as we know, none of these gene products have direct links to

573 ribosome production. During the embryo-to-larva transition, only the four MB NBs and one

574 Antennal lobe $(A L)$ NBs continue to proliferate independently of dietary nutrients and PI3-kinase 
575 activity (Kunz et al., 2012; Prokop and Technau, 1994; Ito and Hotta, 1992; Lin et al., 2013; Sipe

576 and Siegrist, 2017). The majority of other NBs, however, enter a period of quiescence (Kunz et

577 al., 2012; Prokop and Technau, 1994; Ito and Hotta, 1992) and require dietary nutrients and

578 PI3-kinase activity to exit quiescence $24 \mathrm{hrs}$ after hatching (Lovick and Hartenstein, 2015; Sipe

579 and Siegrist, 2017). During subsequent larval development, each MB NBs generates an almost

580 identical repertoire of intrinsic Kenyon cells and continues to proliferate on into the pupal stages

581 ( 85-90 hours after pupa formation) (Ito and Hotta, 1992; Ito et al., 1997). As a result, the adult

582 MB neuropil in each CB lobe is densely packed with around 2000-3000 Kenyon cells per lobe

583 (Technau and Heisenberg, 1982; Aso et al., 2009).

$584 \quad$ Thus the MB NBs (and AL NBs) are inherently different in their proliferative schedules

585 compared to the rest of the neuroblasts in the Drosophila larval brain. This may explain in part

586 their resilience to nucleolar stress; that is, continued neuroblast proliferation and already high

587 synthetic rates (e.g., ribosome production) may sustain the MB NBs upon nucleolar stress at

588 least temporarily, while the other NBs may not be able to rekindle high synthetic levels as they

589 exit quiescence (Bertoli et al., 2013).

\section{Phenotypes}

For the first time, we showed that the Nopp140 gene in Drosophila is haplo-insufficient where $J 11^{\text {DsRed }} / T M 3$ displayed embryonic lethality (Fig. 4A). This was a surprise since a

594 previous segmental aneuploidy study indicated no haplo-insufficiency genes existed in

595 cytological region 78F4 of the left arm of chromosome 3 (Lindsley et al., 1972). Haplo-

596 insufficiency of the Drosophila Nopp140 gene would be analogous to haplo-insufficiency of the

597 human Tcof1 gene which encodes treacle, a vertebrate early RBF related to Nopp140 in

598 structure and function. Loss of treacle in Tcof1+/- human embryos results in the Treacher

599 Collins syndrome, a ribosomopathy leading to apoptosis in select embryonic neural crest cells

600 ultimately leading to the craniofacial birth defects.

$601 \quad$ Earlier work in our lab showed that complete loss of Nopp140 in Drosophila induced

602 nucleolar stress with the redistribution of the C/D box methyl-transferase, fibrillarin, to the

603 nucleoplasm (He et al., 2015). Here, we showed that Nopp140 transcripts and at least the

604 Nopp140-RGG isoform were reduced but not completely absent in early larvae homozygous for 605 the disrupted Nopp140 allele, J11 non-DsRed, (Figs 2, 3). Interestingly, each wild type central brain 606 lobe showed four anterior cells that appeared to contain more Nopp140-RGG than other cells 607 within the same lobes (Fig. 3). The observation suggested that MB NBs contain more Nopp140 608 than do other NBs. We then showed that mCD8::GFP-labeled MB lineages in homozygous 
$609 J 11^{\text {non-DsRed }}$ larvae retained nucleolar fibrillarin, whereas fibrillarin was noticeably redistributed to 610 the nucleoplasm in the majority of other NBs (Fig. 8). This latter observation indicated that

611 nucleoli in the MB lineages preferentially retained more RBFs and perhaps maintained

612 functional production of ribosomes longer, although to what extent requires future molecular

613 analyses.

\section{Differential Expressions}

Most cells within the central brain lobes of homozygous $J 11^{\text {non-DsRed }}$ larvae 1-2 day ALH

617 showed reduced anti-Nopp140-RGG labeling compared to brain cells in similarly aged wild type

618 larvae. Interestingly, wild type larvae clearly showed four cells, identified as MB NBs, per central

619 brain lobe with prominent anti-Nopp140-RGG labeling (Fig. 3). The observation suggests that

620 wild type MB NBs contain more zygotically expressed Nopp140 than do other NBs. Recent

621 findings supporting this notion show that various RBFs such as treacle, fibrillarin, Nop56, mbm,

622 and NS3 are overexpressed in stem cell and progenitor cell populations (Brombin et al., 2015;

623 Watanabe-Susaki et al., 2014; Wang et al., 2013; Johnson et al., 2018; Hovhanyan et al., 2014;

624 Hartl et al., 2013; Dixon et al., 2006), and that the quantity and spatiotemporal expression of

625 RBFs can vary in different stem cell or progenitor cell populations (Weiner et al., 2012; Bouffard

626 et al., 2018). A selective expression of not only Nopp140, but other RBFs such as fibrillarin,

627 Nop56, Nop60b (Fig. 9A) in MB NBs during the embryo-to-larva transition period may explain

628 the resilience of MB lineages to nucleolar stress later during larval development.

629 Related to differential expression of RBFs in stem cells and progenitor cells is the

630 perplexing problem of why some larvae homozygous for the disrupted Nopp140 gene survive up

631 to day $24 \mathrm{ALH}$ (Fig. 4B). While we have yet to pursue this question rigorously, we suspect these

632 Nopp140-/- individuals may inherent more maternal Nopp140 mRNA and/or protein, and this

633 may be a function of the nutrition and health of the mothers. Earlier work in our lab (McCain et

634 al., 2006) followed maternally expression of GFP-Nopp140 into embryogenesis, and we noted

635 then that the protein has a long lifespan, on the order of several days. Individual Nopp140-/-

636 embryos that inherited extra maternal Nopp140 transcripts or protein would likely produce more

637 ribosomes and survive longer.

638

639 The Possibility of Heterogeneous Ribosomes

640 Ribosomes are not all the same even within a single cell (Xue and Barna, 2012; Guo

641 2018). Werner et al. (2015) showed that the translation program of human embryonic stem

642 cells (hESCs) differentiating into neural crest cells changed after the depletion of KBTBD8, a 
643 substrate adapter for the vertebrate-specific ubiquitin ligase, CUL3. CUL3 mono-ubiquitylates

644 human Nopp140 (NOLC1) and treacle, and forms a Nopp140-treacle platform that connects

645 RNA Pol I machinery with ribosome modification factors. Based on these results, the authors

646 hypothesized that the change in translational profile was the result of differential alteration of

647 ribosomes. Modifications such as rRNA pseudouridylation and methylation, or phosphorylation

648 and ubiquitylation of ribosomal proteins or ribosome-associated factors may ultimately

649 contribute to translational control of gene expression (Sloan et al., 2017). Thus, the abundance

650 of Nopp140 in different Drosophila neuroblasts could potentially lead to differential modifications

651 of the ribosome pool, and thus changes in the translational profile in different neuroblasts.

652 Finally, transcriptome profiles (Fig. 9 and Supplemental Fig. 5) of the different

653 Drosophila larval brain neuroblasts indicated that RBFs fibrillarin, Nop140, Nop60, and Nop56

654 are expressed at higher levels in the MB NBs. Of the ribosomal proteins, RpL41 had the highest

655 expression levels in all brain cells, but was again highest in the MB NBs (indicated by an

656 asterisk in Supplemental Fig. S5). Are there heterogeneous pools of ribosomes within a

657 Drosophila larval brain? If so, it might explain why the MB NBs are more resilient to nucleolar

658 stress. The Drosophila nervous system should serve well to explore differential threshold

659 requirements for ribosome production.

660

661 Competing Interests

662 The authors declare no competing or financial interests.

664 Funding

665 This study was funded by the National Science Foundation, grant numbers MCB0919709 and

666 MCB1712975. 

mushroom body of adult Drosophila characterized by GAL4 drivers. J. Neurogenet. 23, 156-172.

Bachellerie, J. P., Cavaillé, J. and Hüttenhofer, A. (2002). The expanding snoRNA world. Biochimie. 84, 775-790.

Bae, S., Park, J. and Kim, J-S. (2014). Cas-OFFinder: a fast and versatile algorithm that searches for potential off-target sites of Cas9 RNA-guided endonucleases. Bioinformatics. 30 , 1473-1475.

Baßler, J. and Hurt, E. (2019). Eukaryotic ribosome assembly. Annu. Rev. Biochem. 88, 281306.

Bertoli, C., Skotheim, J. M. and de Bruin, R. A. M. (2013). Control of cell cycle transcription during G1 and S phases. Nat. Rev. Mol. Cell Biol. 14, 518-528.

Birkholz, O., Rickert, C., Nowak, J., Coban, I. C. and Technau, G. M. (2015). Bridging the gap between postembryonic cell lineages and identified embryonic neuroblasts in the ventral nerve cord of Drosophila melanogaster. Biol. Open. 4, 420-434.

Bouffard, S., Dambroise, E., Brombin, A., Lempereur, S., Hatin, I., Simion, M., Corre, R., Bourrat, F., Joly, J. S. and Jamen, F. (2018). Fibrillarin is essential for S-phase progression and neuronal differentiation in zebrafish dorsal midbrain and retina. Dev. Biol. 437, 1-16.

Brombin, A., Joly, J. S. and Jamen, F. (2015). New tricks for an old dog: ribosome biogenesis contributes to stem cell homeostasis. Curr. Opin. Genet. Dev. 34, 61-70.

Cui, Z. and DiMario, P. J. (2007). RNAi knockdown of Nopp140 induces Minute-like phenotypes in Drosophila. Mol. Biol. Cell. 18, 2179-2191. 
711 genes encoding subunits of RNA polymerases I and III cause Treacher Collins syndrome. Nat.

712 Genet. 43, 20-22.

713

de Cuevas, M. and Spradling, A. C. (1998). Morphogenesis of the Drosophila fusome and its implications for oocyte specification. Development. 125, 2781-2789. and Trainor, P. A. (2006). Tcof1/Treacle is required for neural crest cell formation and proliferation deficiencies that cause craniofacial abnormalities. Proc. Natl. Acad. Sci. USA. 103, 13403-13408.

Doudna, J. A. and Charpentier, E. (2014). The new frontier of genome engineering with CRISPR-Cas9. Science. 346, 1258096-1258096.

Egger, B., Chell, J. M. and Brand, A. H. (2008). Insights into neural stem cell biology from flies. Philos. Trans. R. Soc. B. Biol. Sci. 363, 39-56.

Garneau, N. L., Wilusz, J. and Wilusz, C. J. (2007). The highways and byways of mRNA decay. Nat. Rev. Mol. Cell Biol. 8, 113-126.

Golomb, L., Volarevic, S. and Oren, M. (2014). p53 and ribosome biogenesis stress: The essentials. FEBS Lett. 588, 2571-2579.

Gonzales, B., Henning, D., So, R. B., Dixon, J., Dixon, M. J. and Valdez, B. C. (2005). The Treacher Collins syndrome (TCOF1) gene product is involved in pre-rRNA methylation. Hum Mol. Genet. 14, 2035-2043. M., Wildonger, J. and O'Connor-Giles, K. (2013). Genome engineering of Drosophila with the CRISPR RNA-guided Cas9 nuclease. Genetics 194, 1029-1035.

742 Gratz, S. J., Ukken, F. P., Rubinstein, C. D., Thiede, G., Donohue, L. K., Cummings, A. M.

743 and O'Connor-Giles, K. M. (2014). Highly specific and efficient CRISPR/Cas9-catalyzed

744 homology-directed repair in Drosophila. Genetics. 196, 961-971. 
Guo, H. (2018). Specialized ribosomes and the control of translation. Biochem. Soc. Trans. 46, 855-869.

Hartenstein, V. and Wodarz, A. (2013). Initial neurogenesis in Drosophila. Wiley Interdiscip.

Rev. Dev. Biol. 2, 823-823.

Kaplan, D. D., Johnson, A. W. and Scott, M. P. (2013). Regulation of ribosome biogenesis by nucleostemin 3 promotes local and systemic growth in Drosophila. Genetics. 194, 101-115.

Hayano, T., Yanagida, M., Yamauchi, Y., Shinkawa, T., Isobe, T. and Takahashi, N. (2003). Proteomic analysis of human Nop56p-associated pre-ribosomal ribonucleoprotein complexes. J. Biol. Chem. 278, 34309-34319.

He, F. and DiMario, P. J. (2011). Drosophila delta-1-pyrroline-5-carboxylate dehydrogenase (P5CDh) is required for proline breakdown and mitochondrial integrity - Establishing a fly model for human type II hyperprolinemia. Mitochondrion. 11, 397-404. Nopp140 induces subcellular ribosomopathies. Chromosoma. 124, 191-208.

Homem, C. C. and Knoblich, J. A. (2012). Drosophila neuroblasts: a model for stem cell biology. Development. 139, 4297-4310.

$771 \mathrm{mbm}$ is a nucleolar myc and casein kinase 2 target required for ribosome biogenesis and cell

772 growth of central brain neuroblasts. Mol. Cell. Biol. 34, 1878-1891.

775 mushroom body is a quadruple structure of clonal units each of which contains a virtually

776 identical set of neurones and glial cells. Development. 124, 761-771. 
Ito, K. and Hotta, Y. (1992). Proliferation pattern of postembryonic neuroblasts in the brain of Drosophila melanogaster. Dev. Biol. 149, 134-148. Nucleolar stress in Drosophila melanogaster. Nucleus. 4, 123-133. without p53. Nucleus. 5, 402-426.

Jinek, M., Chylinski, K., Fonfara, I., Hauer, M., Doudna, J. A. and Charpentier, E. (2012). A programmable dual-RNA-guided DNA endonuclease in adaptive bacterial immunity. Science. 337, 816-821.

Johnson, P. W., Doe, C. Q. and Lai, S-L. (2018). Drosophila nucleostemin 3 is required to maintain larval neuroblast proliferation. Dev. Biol. 440, 1-12.

Jones, N. C., Lynn, M. L., Gaudenz, K., Sakai, D., Aoto, K., Rey, J. P., Glynn, E. F., Ellington, L., Du, C., Dixon, J., et al. (2008). Prevention of the neurocristopathy Treacher Collins syndrome through inhibition of p53 function. Nat. Med. 14, 125-133. and control body size. Genes Dev. 22, 1877-1893.

Knott, G. J. and Doudna, J. A. (2018). CRISPR-Cas guides the future of genetic engineering.

Kressler, D., Hurt, E. and Baßler, J. (2010). Driving ribosome assembly. Biochim. Biophys. Acta. 1803, 673-683. 
812 Lai, S-L. and Doe, C. Q. (2014). Transient nuclear Prospero induces neural progenitor

813 quiescence. Elife. 3.

814

Lambertsson, A. (1998). The Minute genes in Drosophila and their molecular functions. Adv. Genet. 38, 69-134. Truman, J. W. and Lee, T. (2013). Extremes of lineage plasticity in the Drosophila brain. Curr. Biol. 23, 1908-1913. Jacobs, P. A., Miklos, G. L., Davis, B. K., Gethmann, R. C. et al. (1972). Segmental aneuploidy and the genetic gross structure of the Drosophila genome. Genetics. 71, 157-184.

Long, E. O. and Dawid, I. B. (1980). Alternative pathways in the processing of ribosomal RNA precursor in Drosophila melanogaster. J. Mol. Biol. 138, 873-878.

Lovick, J. K. and Hartenstein, V. (2015). Hydroxyurea-mediated neuroblast ablation establishes birthdates of secondary lineages and addresses neuronal interactions in the developing Drosophila brain. Dev. Biol. 402, 32-47.

Macinnes, A. W. (2016). The role of the ribosome in the regulation of longevity and lifespan extension. Wiley Interdiscip. Rev. RNA. 7, 198-212.

Marygold, S. J., Roote, J., Reuter, G., Lambertsson, A., Ashburner, M., Millburn, G. H., Harrison, P. M., Yu, Z., Kenmochi, N., Kaufman, T. C., et al. (2007). The ribosomal protein genes and Minute loci of Drosophila melanogaster. Genome Biol. 8, R216. dynamics with GFP-Nopp140 during Drosophila oogenesis and embryogenesis. Cell Tissue Res. 323, 105-115. 
Meier, U. T. (1996). Comparison of the rat nucleolar protein Nopp140 with its yeast homolog SRP40. J. Biol. Chem. 271, 19376-19384.

Narla, A. and Ebert, B. L. (2010). Ribosomopathies: Human disorders of ribosome dysfunction. roles of RNA polymerase I and III subunits Polr1c and Polr1d in craniofacial development and in zebrafish models of Treacher Collins Syndrome. PLoS Genet. 12, e1006187. efficient germline and somatic engineering in Drosophila. Proc. Natl. Acad. Sci. USA 111, E2967-E2976.

Prokop, A. and Technau, G. M. (1994). Normal function of the mushroom body defect gene of Drosophila is required for the regulation of the number and proliferation of neuroblasts. Dev. Biol. 161, 321-337. E. M. (1987). Monoclonal autoantibody from a (New Zealand black x New Zealand white) $F_{1}$ mouse and some scleroderma sera target an $M_{r} 34,000$ nucleolar protein of the U3 RNP particle. Arthritis Rheum. 30, 793-800. Sun, L., et al. (2013). Optimized gene editing technology for Drosophila melanogaster using germ line-specific Cas9. Proc. Natl. Acad. Sci. USA 110, 19012-19017.

Renault, A. D. (2012). vasa is expressed in somatic cells of the embryonic gonad in a sex-

872 specific manner in Drosophila melanogaster. Biol. Open. 1, 1043-1048.

874 Rosby, R., Cui, Z., Rogers, E., deLivion, M. A., Robinson, V. L. and DiMario, P. J. (2009).

875 Knockdown of the Drosophila GTPase nucleostemin 1 impairs large ribosomal subunit 876 biogenesis, cell growth, and midgut precursor cell maintenance. Mol. Biol. Cell. 20, 4424-4434. 
Sakai, D. and Trainor, P. A. (2009). Treacher Collins syndrome: unmasking the role of Tcof1/treacle. Int. J. Biochem. Cell Biol. 41, 1229-1232.

Sipe, C. W. and Siegrist, S. E. (2017). Eyeless uncouples mushroom body neuroblast proliferation from dietary amino acids in Drosophila. Elife. 6, e26343.

Sloan, K. E., Warda, A. S., Sharma, S., Entian, K-D., Lafontaine, D. L. J. and Bohnsack, M. biogenesis and function. RNA Biol. 14, 1138-1152.

Technau, G. and Heisenberg, M. (1982). Neural reorganization during metamorphosis of the corpora pedunculata in Drosophila melanogaster. Nature. 295, 405-407.

Thum, A. S. and Gerber, B. (2019). Connectomics and function of a memory network: the mushroom body of larval Drosophila. Curr. Opin. Neurobiol. 54, 146-154.

Tsai, R. Y. L. and Pederson, T. (2014). Connecting the nucleolus to the cell cycle and human disease. FASEB J. 28, 3290-3296.

Tsai, R. Y. L. (2011). New frontiers in nucleolar research: nucleostemin and related proteins. In The Nucleolus (ed. M. O. J. Olson), pp. 301-320. New York: Springer.

Urbach, R. and Technau, G. M. (2003). Molecular markers for identified neuroblasts in the developing brain of Drosophila. Development. 130, 3621-3637.

Waggener, J. M. and DiMario, P. J. (2002). Two splice variants of Nopp140 in Drosophila melanogaster. Mol. Biol. Cell. 13, 362-381.

Wang, C., Query, C. C. and Meier, U. T. (2002). Immunopurified small nucleolar

907 ribonucleoprotein particles pseudouridylate rRNA independently of their association with

908 phosphorylated Nopp140. Mol. Cell. Biol. 22, 8457-8466.

909

910 Wang, H. D., Kazemi-Esfarjani, P. and Benzer, S. (2004). Multiple-stress analysis for isolation 911 of Drosophila longevity genes. Proc. Natl. Acad. Sci. USA. 101, 12610-12615. 
913 Wang, H., Chen, X., He, T., Zhou, Y. and Luo, H. (2013). Evidence for tissue-specific

914 Jak/STAT target genes in Drosophila optic lobe development. Genetics. 195, 1291-1306.

915

916 Wang, Y. and DiMario, P. (2017). Loss of Drosophila nucleostemin 2 (NS2) blocks nucleolar

917 release of the 60S subunit leading to ribosome stress. Chromosoma. 126, 375-388.

Warner, J. R. (1999). The economics of ribosome biosynthesis in yeast. Trends Biochem. Sci. 24, 437-440.

921

Watanabe-Susaki, K., Takada, H., Enomoto, K., Miwata, K., Ishimine, H., Intoh, A., Ohtaka, M., Nakanishi, M., Sugino, H., Asashima, M., et al. (2014). Biosynthesis of ribosomal RNA in nucleoli regulates pluripotency and differentiation ability of pluripotent stem cells. Stem Cells. 32, 3099-3111.

Weiner, A. M., Scampoli, N. L. and Calcaterra, N. B. (2012). Fishing the molecular bases of Treacher Collins syndrome. PLoS One. 7, e29574. Ingolia, N. T. and Rape, M. (2015). Cell-fate determination by ubiquitin-dependent regulation of translation. Nature. 525, 523-527.

Woolford, J. L. Jr. and Baserga, S. J. (2013). Ribosome biogenesis in the yeast Saccharomyces cerevisiae. Genetics. 195, 643-681.

Xue, S. and Barna, M. (2012). Specialized ribosomes: a new frontier in gene regulation and organismal biology. Nat. Rev. Mol. Cell Biol. 13, 355-369.

Yang, C. P., Fu, C. C., Sugino, K., Liu, Z., Ren, Q., Liu, L. Y., Yao, X., Lee, L. P. and Lee, T.

941 (2016). Transcriptomes of lineage-specific Drosophila neuroblasts profiled by genetic targeting

942 and robotic sorting. Development. 143, 411-421.

944 Yang, K., Yang, J. and Yi, J. (2018). Nucleolar Stress: hallmarks, sensing mechanism and 945 diseases. Cell Stress. 2, 125-140. 
Yang, Y., Isaac, C., Wang, C., Dragon, F., Pogačić, V. and Meier, U. T. (2000). Conserved composition of mammalian Box $\mathrm{H} / \mathrm{ACA}$ and Box $\mathrm{C} / \mathrm{D}$ small nucleolar ribonucleoprotein particles and their interaction with the common factor Nopp140. Mol. Biol. Cell. 11, 567-577.

Zhong, W. and Chia, W. (2008). Neurogenesis and asymmetric cell division. Curr. Opin.

952 Neurobiol. 18, 4-11.

\section{Figure Legends}

Fig. 1. Anatomy of the Drosophila larval brain and overall hypothesis. A Larval brains have two central brain lobes and a ventral nerve cord (VNC). There are roughly five neuroblast (NB) types within the larval brain: Type I (grey), Type II (red), Mushroom body (green), Antennal lobe (neon), and Optic lobe (blue). These NBs are shown in their putative locations within the larval brain. B Our hypothesis is that upon nucleolar stress due to loss of Nopp140, different neuroblast lineages exhibit variable phenotypes ranging from a mild to severe loss of lineage progeny cells, to compete loss of the lineage altogether.

Fig. 2. CRISPR-mediated disruption of the Nopp140 gene and RT-PCR analysis. A Three plasmids encoding guide RNAs, gRNA\#52 and gRNA\#99, or the DsRed protein were injected into embryos from the nanos-Cas9 fly line. The guide RNAs directed Cas 9 cleavage at two specific sites located 321 base pairs apart in the second exon of the Nopp140 gene (blue bar; 1650 bp total). The DsRed gene (red arrow) with flanking plasmid sequences (light grey) and 3' and 5' Nopp140 homology arms inserted into the deletion by homology directed repair (HDR). Seven heterozygous Nopp140 disruption lines were identified by DsRed expression in adult

972 eyes. The DsRed gene was subsequently mutated (dark grey arrow) by CRISPR-mediated

973 mutagenesis. B Genomic PCRs using a DsRed-specific forward primer (grey) and a

974 downstream Nopp140-specific reverse primer (blue half arrow in panel A) verified the DsRed

975 insertion within the second exon of Nopp140 gene in all seven Nopp140 heterozygous

976 disruption lines (J11, J47, J54, J60, K13, M6, M20) with the expected 1836 bp product. The

$977 w^{1118} \mathrm{fly}$ line served as negative control. C RT-PCR analyses of Nopp140 transcript levels in

978 control $w^{1118}$ and homozygous $J 11^{\text {non-DsRed }}$ larvae day 1-2 ALH using the Exon2 reverse primer

979 (blue half arrow) for first strand cDNA synthesis. Subsequent PCRs used the same Exon2 
reverse primer and a forward primer specific for the first intron of the Nopp140 gene. A representative gel is provided. No PCR products appeared in the minus-RT controls. Band intensity ratios $\left(J 11 / w^{1118}\right)$ were determined for three biological replicates with overall mean $+/$ SEM of $0.61+/-0.022$. Student's t-test: two-tailed with equal variance for three biological replicates $(1,2,3)$ with three PCR technical replicates each, $p$-values $=0.037^{\star}, 0.00081^{* *}$, $0.0064^{* * *}$ respectively. No RT-PCR product was detected using the pDsRed reverse primer (grey half arrow) in the $J 11^{\text {non-DsRed }}$ disruption line. D RT-PCR analyses of ETS, ITS2, Hsp26, RpL32, and Actin5C transcript levels were carried out in control $w^{1118}$ larvae at day 1-2 ALH and in homozygous $J 11^{\text {DsRed }}$ larvae at two time points, day 1-2 and 5-7 ALH using gene-specific reverse primers. Three biological replicates were performed. For each replicate, total RNA was extracted from $\sim 300 w^{1118}$ and 150-300 homozygous $J 11$ larvae. PCR reactions were carried out in triplicate for each first strand cDNA. Representative gels are shown.

Fig. 3. Maternal Nopp140 protein is reduced in early $\mathbf{J 1 1}$ Nopp140-/- larval brains. Central

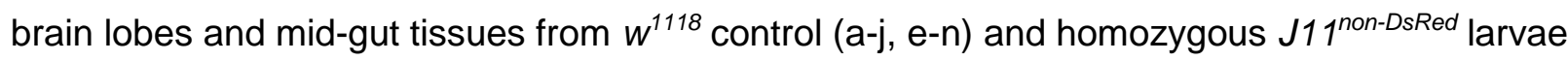
(c-l, g-p) at day 1-2 (a-h) and day 4-5 (i-p) ALH were immunostained with anti-Nopp140-RGG. Arrow in panel a indicates four neuroblasts per wild type brain lobe with large nucleoli labeled with anti-Nopp140-RGG. $\mathrm{n}=19\left(w^{1118}\right)$; $\mathrm{n}=23$ (homozygous $J 11^{\text {non-DsRed }}$; 2 technical replicates. Scale bars: $10 \mu \mathrm{m}$ in panels a-f, $\mathrm{m}-\mathrm{p} ; 25 \mu \mathrm{m}$ in panels $\mathrm{g}-\mathrm{I}$ assays were performed for homozygous $J 11^{\text {DsRed }}$ or heterozygous $J 11^{\text {DsRed }} / T M 3-G F P$ embryos, and for $w^{1118}$ control embryos. Freshly laid eggs were collected from well-yeasted juice plates $(\mathrm{n}$ $=2$; total number of embryos per replicate for $w^{1118}: 200$ and 299, and for J11 $1^{\text {DsRed }} /$ TM3-GFP stock: 230 and 111). The number of hatched larvae were logged for the next two days, and the percent viable embryos was determined. Data shows the number of larvae hatched divided by the total number of embryos collected $X 100 \%$. B Plot shows three replicates (number of larvae

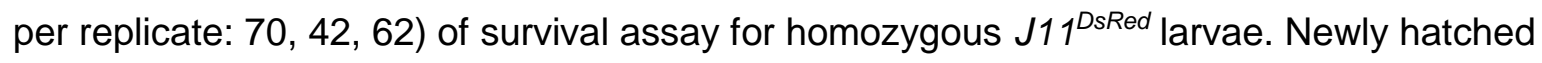
larvae were collected from a well-yeasted juice plates, and the number of living larvae were recorded in the following days until all larvae had perished. $\mathbf{C}$ Embryonic lethality and larval survivability upon Nopp140 depletion by RNAi expression using the worniu::GAL4 driver (specific for all embryonic and larval neuroblasts) and UAS::TComC4.2 (Nopp140-RNAi line; Cui and DiMario 2007). Compared to $86.7 \%$ of the $w^{1118}$ embryos, only $46.8 \%$ of the collected 
1014 larvae, after which all larvae developed into adults (not shown). $n=3$; total number of embryos collected per replicate for each genotype: 200, 265, and 330; Student's t-test: two-tailed with unequal variance, $p$-value $=0.0069$

Fig. 5. Drosophila larval brain development is impaired under nucleolar stress induced by the loss of Nopp140. A Larval brain development in homozygous K0121 (Nopp140 gene deletion, He et al. 2015), homozygous $J 11$ (CRISPR-mediated Nopp140 disruption), and wild1021 type $\left(w^{1118}\right)$ starting at day 1 after larval hatching (ALH) until day 7 and day 13 ALH.

1022 Homozygous KO121 and $J 11$ larval brains at day 13 ALH are shown, but wild-type individuals 1023 have developed into adults by day $13 \mathrm{ALH}$, hence an adult fly brain is shown. B RNAi-depletion 1024 of Nopp140 using pan-neuronal GAL4 driver, Neurotactin (Nrt)::GAL4, and the UAS::TComC4.2 1025 (Nopp140 RNAi line) resulted in impaired larval brain development similar to that seen in 1026 Nopp140 homozygous deletion background. Representative larval brains from three independent crosses at day 4-5 ALH comparing Nopp140-depleted brains with control sibling brains (not expressing RNAi) are shown. Scale bar: $100 \mu \mathrm{m}$ C Conventional fluorescence images of the neuropil immunostained with antibody against Discs large (Dlg; green) in second instar $w^{1118}$ control larvae and homozygous $J 11^{\text {DsRed }}$ larvae at day 2-3 ALH. White arrows show unstained peripheral cell body layers which are reduced in homozygous $J 11^{\text {non-DsRed }}$ larvae. $\mathrm{n}=15$ (wild-type); $\mathrm{n}=18$ (homozygous $J 11^{\text {non-DsRed }}$ ); >3 technical replicates. Scale bar: $50 \mu \mathrm{m}$

Fig. 6. Neuroblast proliferation is reduced upon nucleolar stress. Confocal images of homozygous $J 11^{\text {DsRed }}$ and control $w^{1118}$ larval brains at day 1 (a-f), 2-3 (g-l), and 6 (m-r) ALH are shown after EdU-labeling (Click-iT Alexa Fluor 488) followed by anti-Deadpan (anti-Dpn) immunostaining. Dpn-stained cells (magenta) are neuroblasts. After a $2 \mathrm{hr}$ pulse, EdU-labeled S-phase cells (green) were committed to cell division. Arrows indicate four likely Mushroom Body NBs that were EdU- and Dpn-positive and clustered near the anterior of the central brain $(a, b, d, e, g, h)$. Arrowheads indicate a few EdU-positive cells, likely arising from AL MBs, at the lateral side of the central brain (b, e, h). $n=10,15$, and 10 for day $1,2-3$, and 6 respectively for both wild-type and homozygous $J 11^{\text {DsRed }}$ sample; 3 technical replicates. Scale bar: $50 \mu \mathrm{m}$

Fig. 7. Mushroom Body NBs are resilient to nucleolar stress. Larval brains from control $w^{1118}$ and homozygous $\mathrm{J} 11^{\text {non-DsRed }}$ larvae (see the cross scheme in Supplementary Fig S4) at day 3

1046 ALH were used for 30 min EdU pulse labeling (Click-iT Alexa Fluor 594). Merged confocal 1047 images show EdU-labeled cells (magenta) nestled within the GFP-labeled MB lineage (green) 
near the anterior of the central brains. $\mathrm{n}=12$ (control); $\mathrm{n}=20$ (homozygous $J 11^{\text {non-DsRed }}$; 3 technical replicates. Scale bars: $50 \mu \mathrm{m}$ in panels a-d, $25 \mu \mathrm{m}$ in panels e-h

Fig. 8. Mushroom Body lineage cells retain nucleolar fibrillarin under nucleolar stress.

1052 Larval brains from control $w^{1118}$ (whole brain in a-c; a central brain lobe in $\mathrm{g}$-j) and homozygous

$1053 J 11^{\text {non-DsRed }}$ larvae (whole brain in d-f; a central brain lobe in k-n) at day 3 ALH were

1054 immunostained with anti-fibrillarin (magenta). Merged images in panels $\mathrm{j}$ and $\mathrm{n}$ were obtained

1055 from confocal images $\mathrm{g}$ and $\mathrm{h}$, and $\mathrm{k}$ and I respectively. Arrows in the homozygous $\mathrm{J} 11^{\text {non-DsRed }}$

1056 larval brains $(k, n)$ indicate nucleolar fibrillarin retained in the MB lineage cells marked by cell

1057 surface protein, mCD8::GFP (green), whereas fibrillarin is redistributed into the nucleoplasm in 1058 surrounding cells. $\mathrm{n}=10$ (wild-type); $\mathrm{n}=10$ (homozygous $\mathrm{J1} 1^{\text {non-DsRed }}$; 2 technical replicates.

1059 Scale bars: $50 \mu \mathrm{m}$ in panels a-j, $25 \mu \mathrm{m}$ in panels $\mathrm{k}-\mathrm{n}$

1060

Fig. 9. Transcriptome analyses of ribosome biogenesis factors in lineage-specific

1062 Drosophila neuroblasts and neurons. Expression levels of Nopp140, fibrillarin, Nop56, and

1063 Nop60B transcripts (A); NS1, NS2, NS3, and NS4 transcripts (B); Deadpan, Prospero, and Elav

1064 (C) in the Drosophila larval NBs and neurons. All NB ( $n=3)$, Mushroom Body (MB) NB $(n=3)$, 1065 Antennal Lobe (AL) NB ( $n=3)$, Type II NB $(n=3)$, neurons $(n=2)$. Transcriptome data obtained 1066 from Yang et al. (2016).

1067

1068

1069

1070

1071

1072

1073

1074

1075

1076

1077

1078

1079

1080

1081 
Table 1. List of primers and their sequences.

\begin{tabular}{|l|l|}
\hline Primer & Sequence \\
\hline gRNA-target\#52sense & 5' GTCGGGGCTTTGCCGGTTCTTCCT 3' \\
\hline gRNA-target\#52antisense & 5' AAACAGGAAGAACCGGCAAAGCCC 3' \\
\hline gRNA-target\#99sense & 5' GTCGCAAGTTGGCTCCTGCTAAGA 3' \\
\hline gRNA-target\#99antisense & 5' AAACTCTTAGCAGGAGCCAACTTG 3' \\
\hline DsRed target-gRNA\#2 sense & 5' GTCGGCTGAAGGTGACCAAGGG 3' \\
\hline DsRed target-gRNA\#2 antisense & 5' AAACCCCTTGGTCACCTTCAGC 3' \\
\hline DsRed target-gRNA\#3 sense & 5' GTCGGCTCCCACTTGAAGCCCT 3' \\
\hline DsRed target-gRNA\#3 antisense & 5' AAACAGGGCTTCAAGTGGGAGC 3' \\
\hline DsRed-Forward & 5' GTGTAGTTCTCGTTGTGGGAGGTGAT 3' \\
\hline DsRed-Reverse & 5' GTGTAGTTCTCGTTGTGGGAGGTGAT 3' \\
\hline Nopp140-Exon2-1556 & 5' TTCTCATTGCCATTGGTAGC 3' \\
\hline First Intron-Forward & 5' ATCTGCGTCCTCCTGATC 3' \\
\hline Exon2 & 5' CTCGGAACTGCTATCCTCGCTG 3' \\
\hline pDsRed & 5' GTATGCTATACGAAGTTATAGAAGAGC 3' \\
\hline 5'HomologyArm-EcoRI-F & 5' GGTGGAATTCGTCTTCGCTTGAAGACTTGGCCT 3' \\
\hline 5'HomologyArm-Notl-R & 5' GTATGCGGCCGCAGAAGGGGGCTTCCTCTAGT 3' \\
\hline 3'HomologyArm-BgllI-F & 5' GTAAAGATCTCCTCGGAACTGCTATCCTCGCTGC 3' \\
\hline 3'HomologyArm-Xhol-R & 5' GAGTCTCGAGGCCAGTGTCGCCAAAAGCAG 3' \\
\hline ETS-Forward & 5' TGCCGACCTCGCATTGTTCGAAATW 3' \\
\hline ETS-Reverse & 5' ACCGAGCGCACATGATAATTCTTCCW3' \\
\hline ITS2-Forward & 5' TGGAGTACTATGGTTGAGGGTTG 3' \\
\hline ITS2-Reverse & 5' CGAACCAACGAAGAATAATAACATAACC 3' \\
\hline Hsp26-Forward & 5' CCCCATCTACGAGCTTGGACTG 3' \\
\hline Hsp26-Reverse & 5' CTTCCAGCTTCAAGATGACCATCCGC 3C \\
\hline RpL32-Forward & 5' CTCACCTATAGAAGACGAAGAAGTTGCTGCTCT 3'' \\
\hline RpL32-Reverse & 5' CTAACTGTTGAATCCTCGTAGGACTTCTCCAACG 3' \\
\hline Actin5C-Forward & \\
\hline Actin5C-Reverse & \\
\hline
\end{tabular}




\section{Figure 1}

A
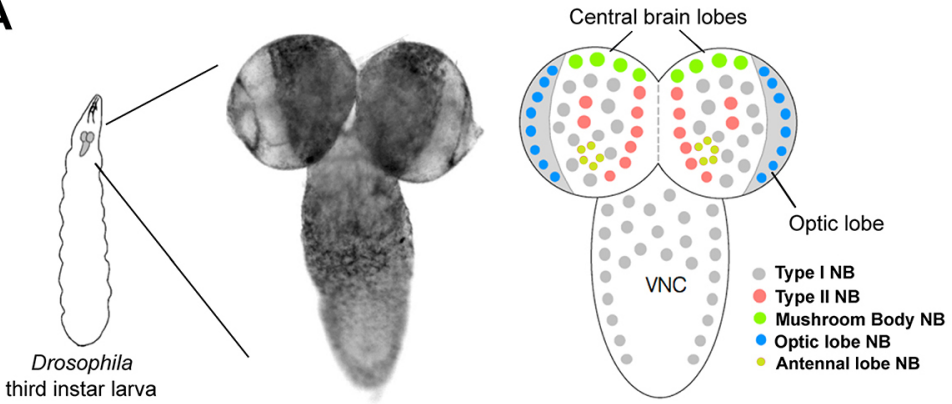

\section{Wild-type}

\section{Loss of Nopp140}
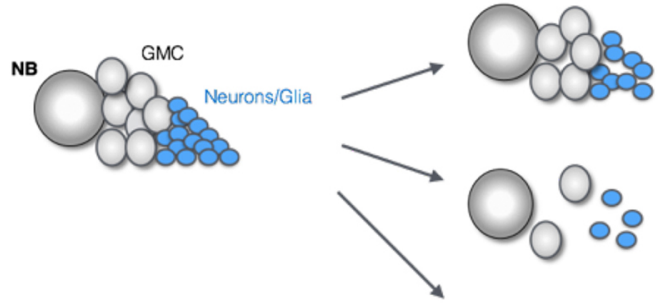

Milder phenotype

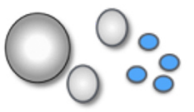

Severe phenotype

Complete loss of lineage 


\section{Figure 2}

A

nanos-Cas9

transgenic flies

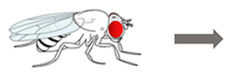

Cas 9 is expressed in germline cells under nanos promoter.

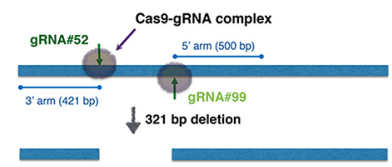

Second exon of Nopp140 (1650 bp)

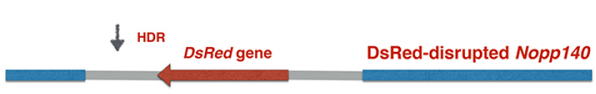

1 CRISPR targeting DsRed gene

Muteded DsRedgene

Non DsRed-disrupted Nopp140

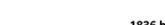

1836 bp

B

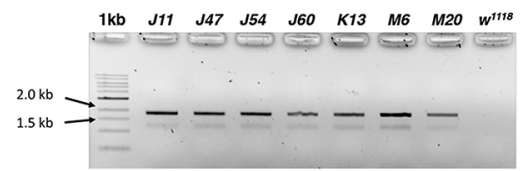

C

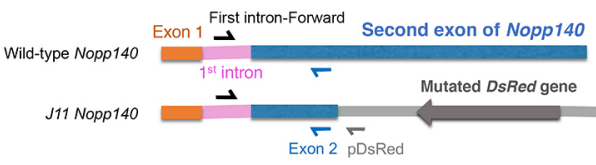

First intron-Forward; Exon 2
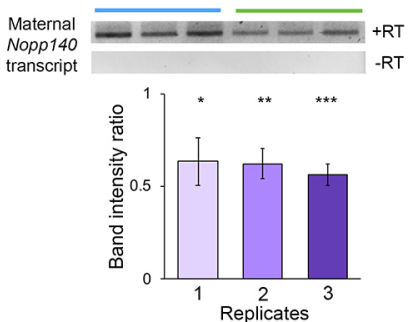

First intron-Forward; pDsRed

$100 \mathrm{pp}$
ladder

J11 non-DsRed Nopp140 transcript

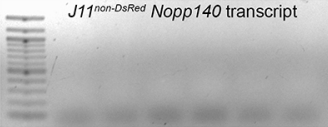

$w^{1718} ;$ Day 1-2 ALH

- J11 non-DsRed ; Day 1-2 ALH

D

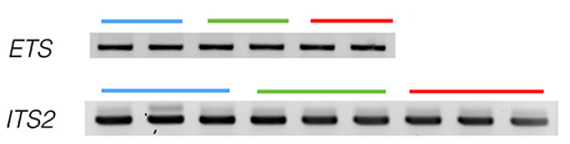

- $w^{\text {t118 }}$; Day 1-2 ALH

- J110sRed; Day 1-2 ALH

- J110sRed; Day 5-7 ALH

Hsp26

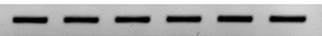

$+R T$

RpL32 - - - - - - - -

$\operatorname{Actin} 5 \mathrm{C}-\mathrm{-}-\mathrm{-}-$ 


\section{Figure 4}

A

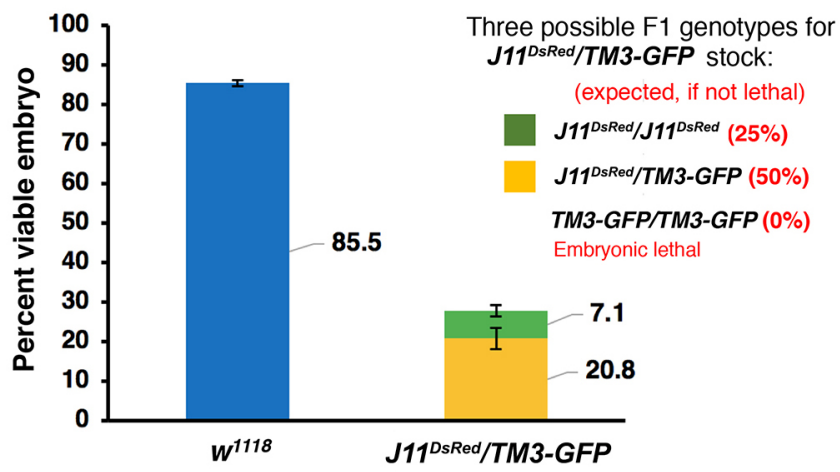

B

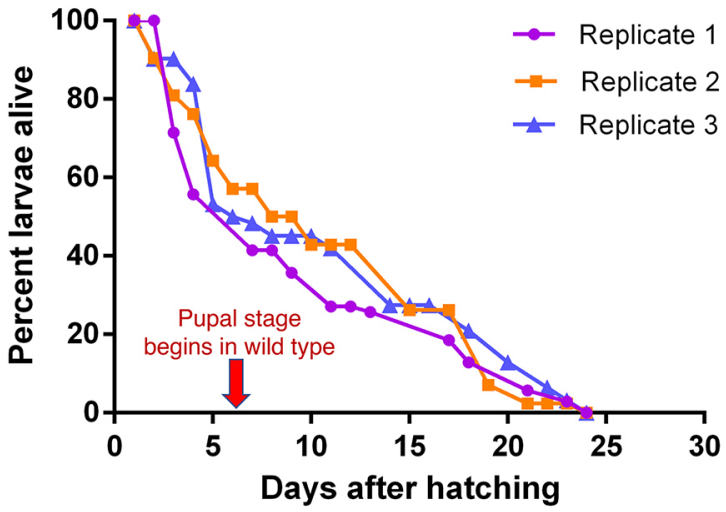

C

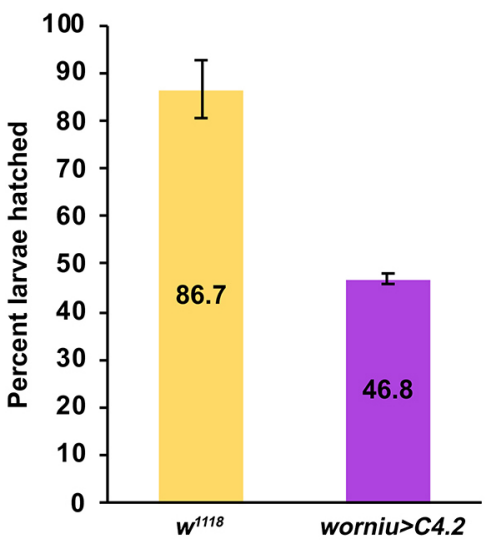




\section{Figure 5}

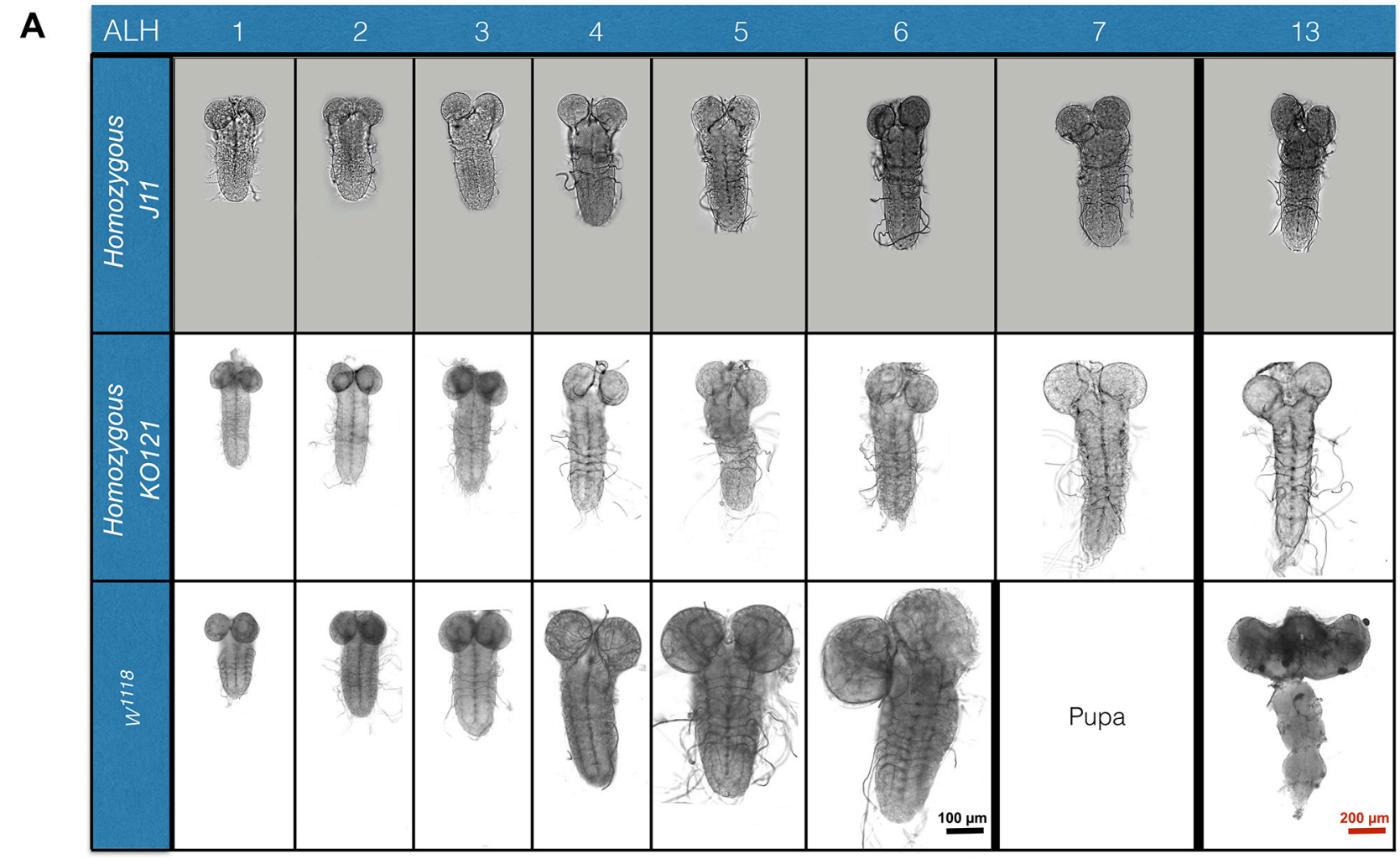

B

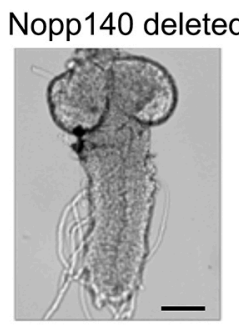

Neurotactin::GAL4>UAS::TComC4.2

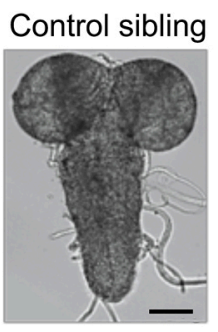

UAS::TComC4.2 no GAL4 driver

Day 4-5 ALH

Wild-type

C
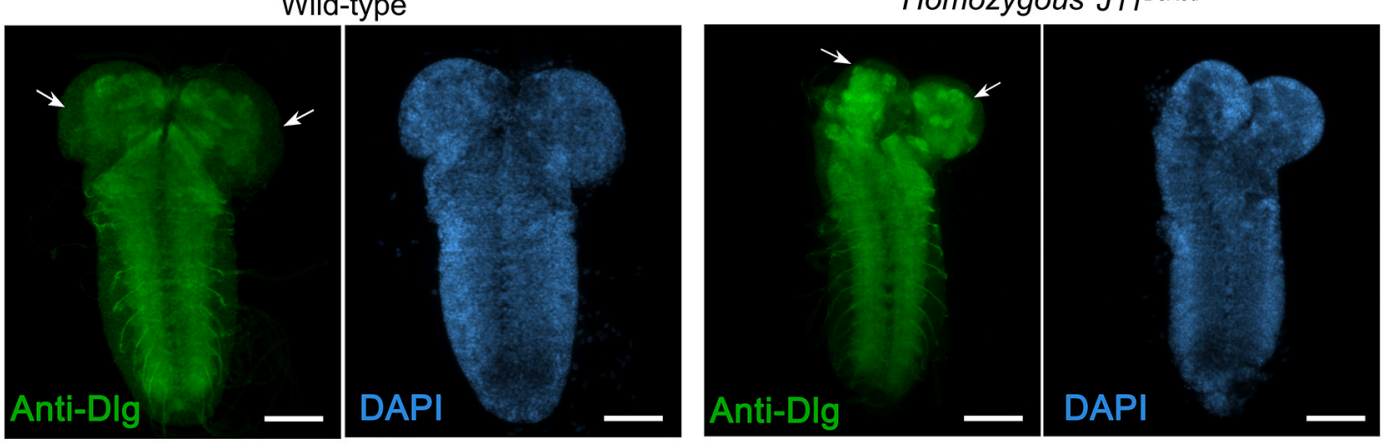

Day 2-3 ALH 
Figure 6

Anti-Dpn

\section{Homozygous}

J11 non-DsRed

Homozygous

J11non-DsRed

Homozygous

J11 non-DsRed

Wild-type a

Wild-type

Wild-type

$$
\text { j }
$$

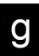

g

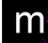

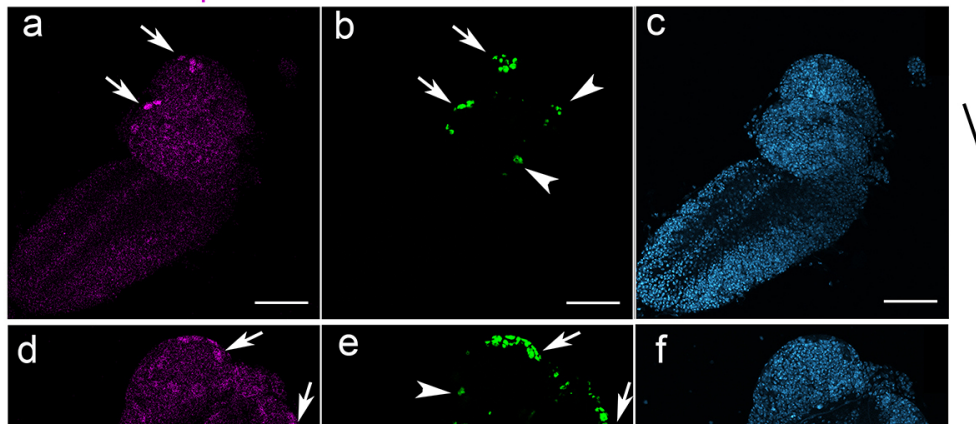

\section{DAPI}

Day $1 \mathrm{ALH}$
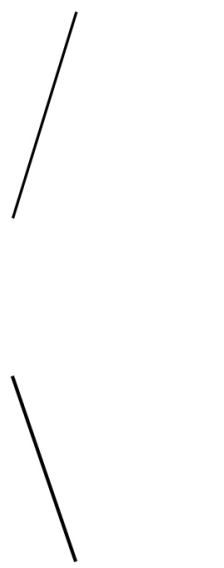

Day 2-3 ALH

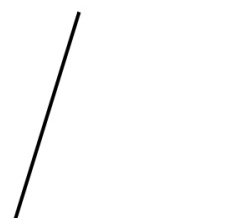

n

n
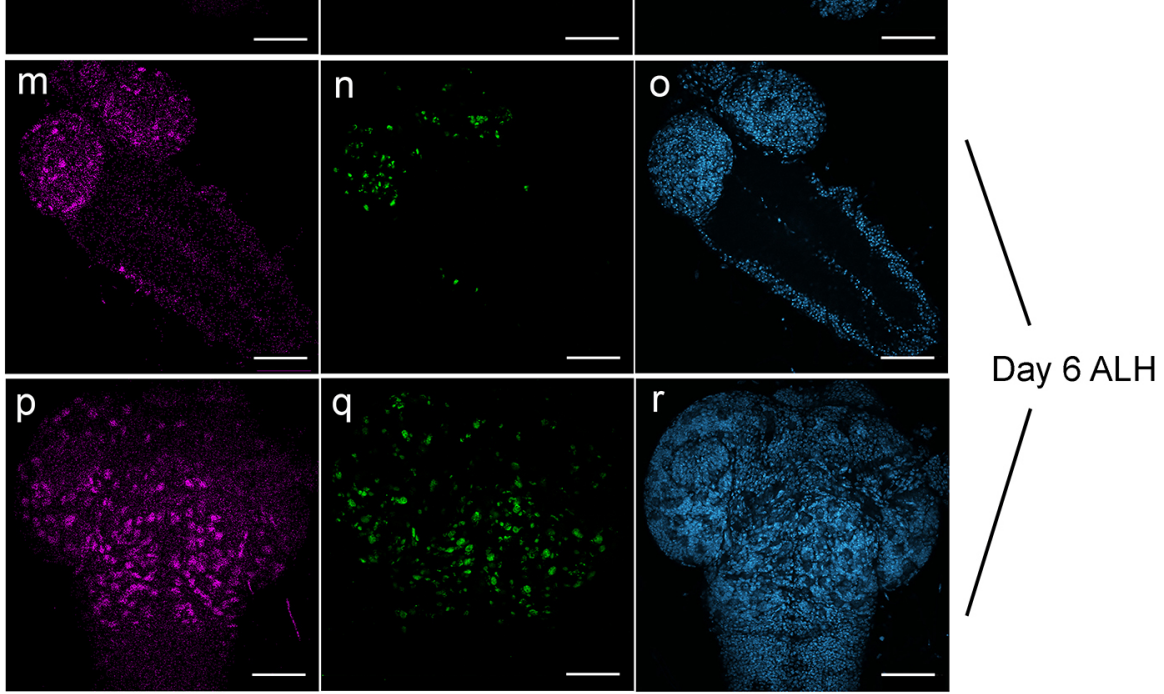
Figure 7

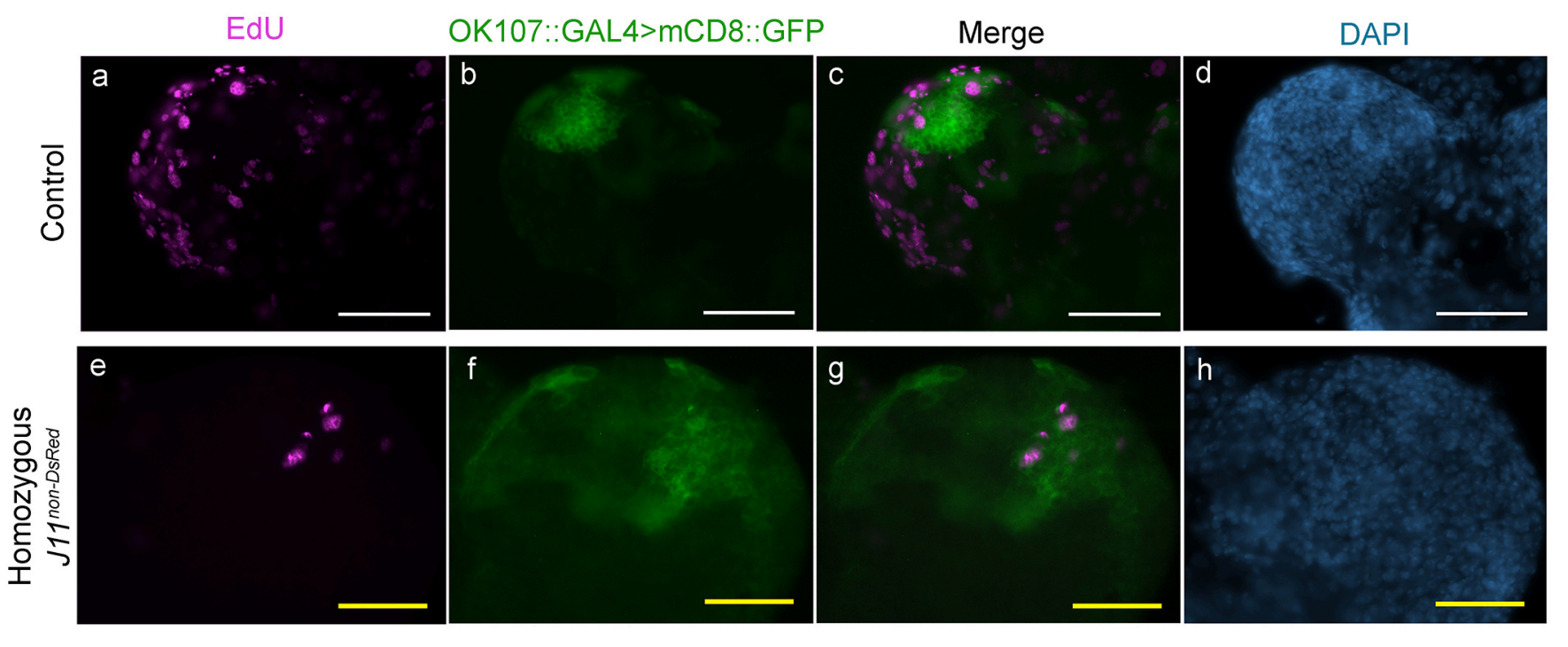




\section{Figure 8}

OK107::GAL4>

Anti-Fibrillarin

a

Wild-type

Homozygous

J11 1non-DsRed

Wild-type

Homozygous J11 11on-DsRed

a

d

d

g

k mCD8::GFP
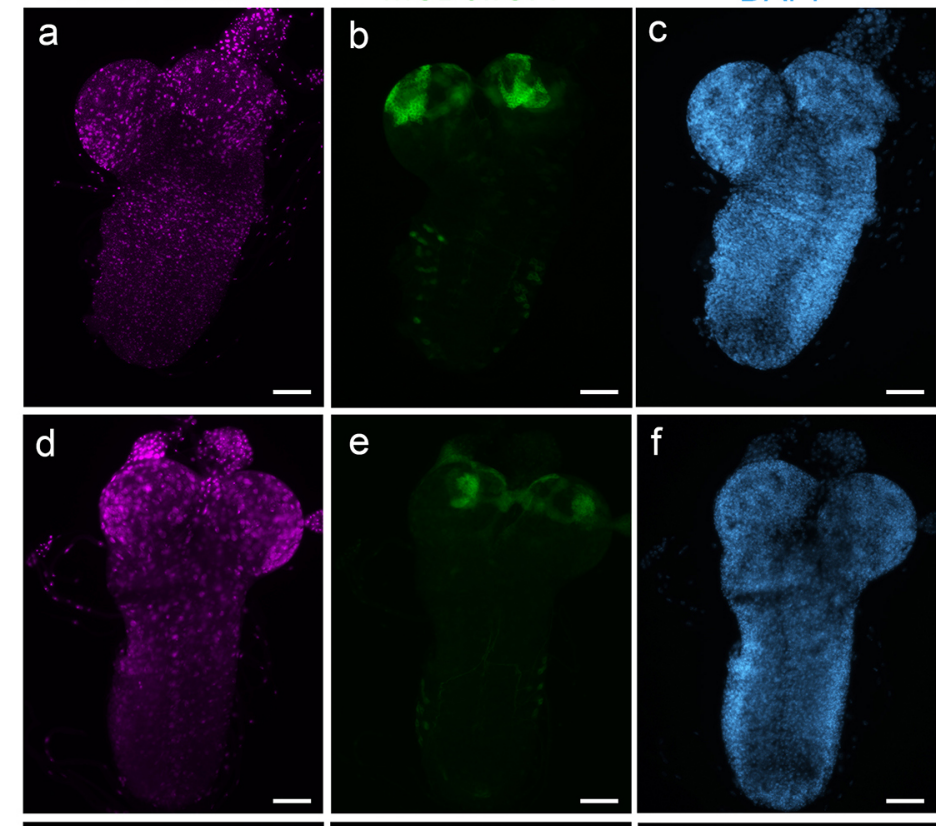

$-$

e

f

C

DAPI

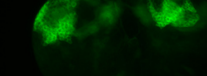

Merge

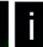

h
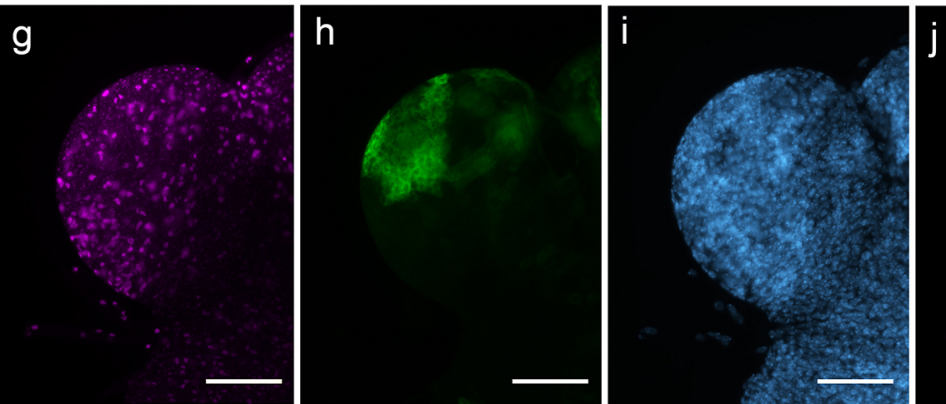

j
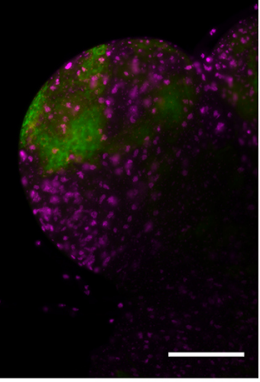

n

$y$
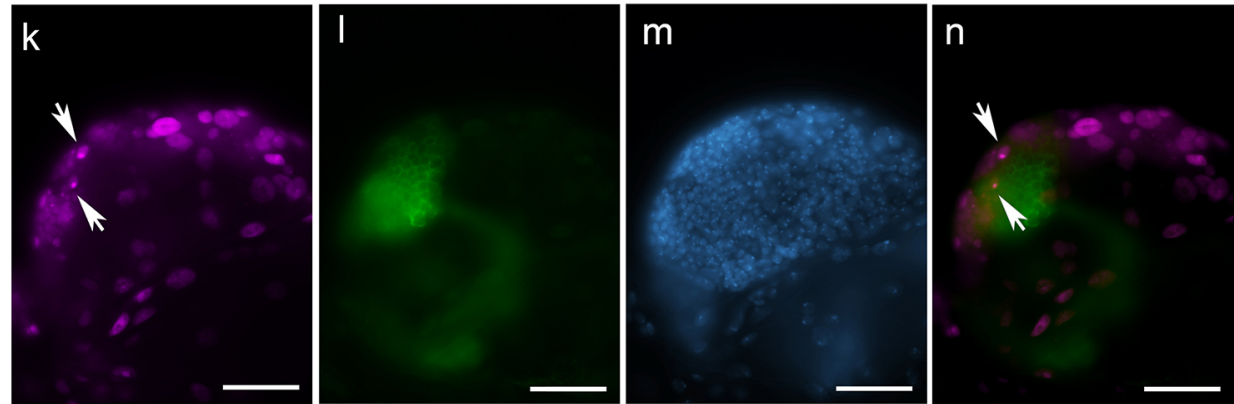


\section{Figure 9}

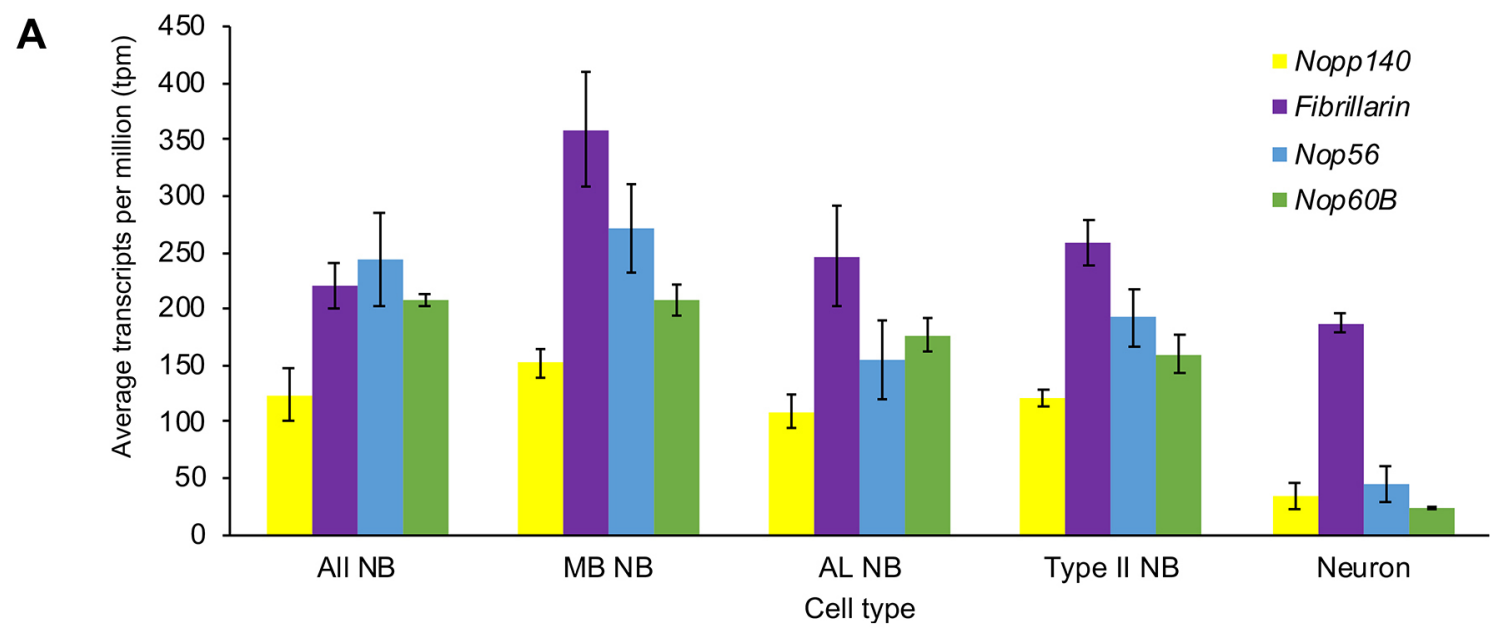

B

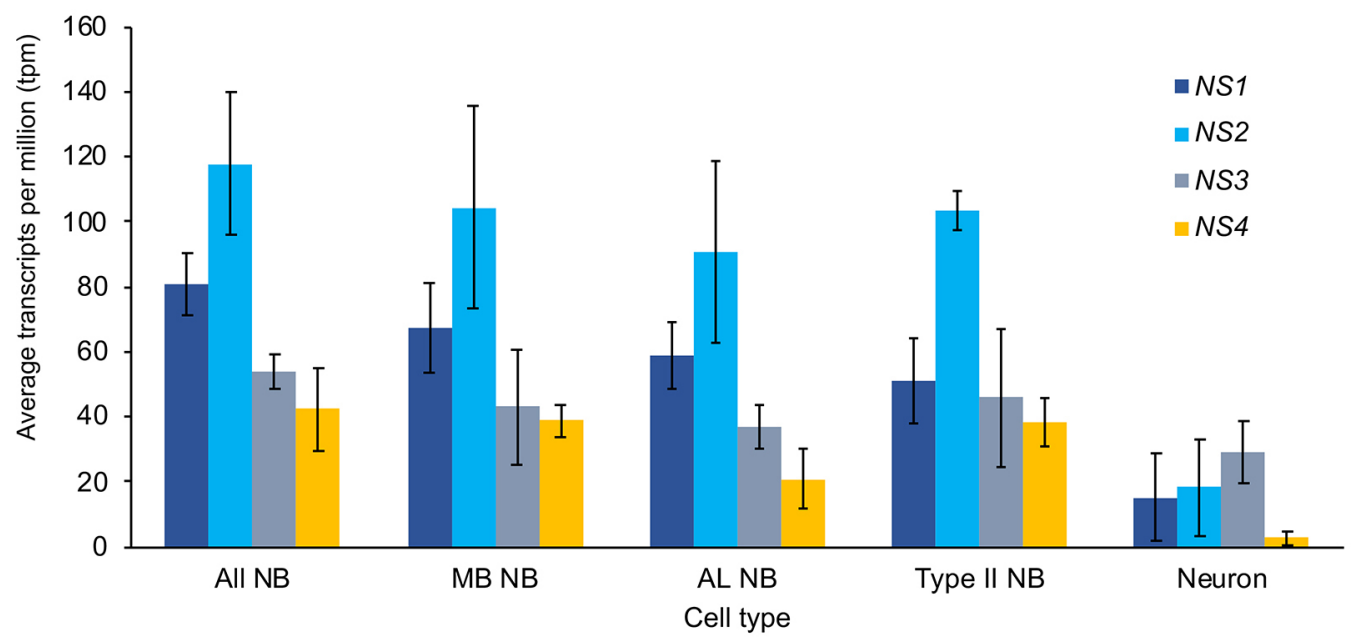

C

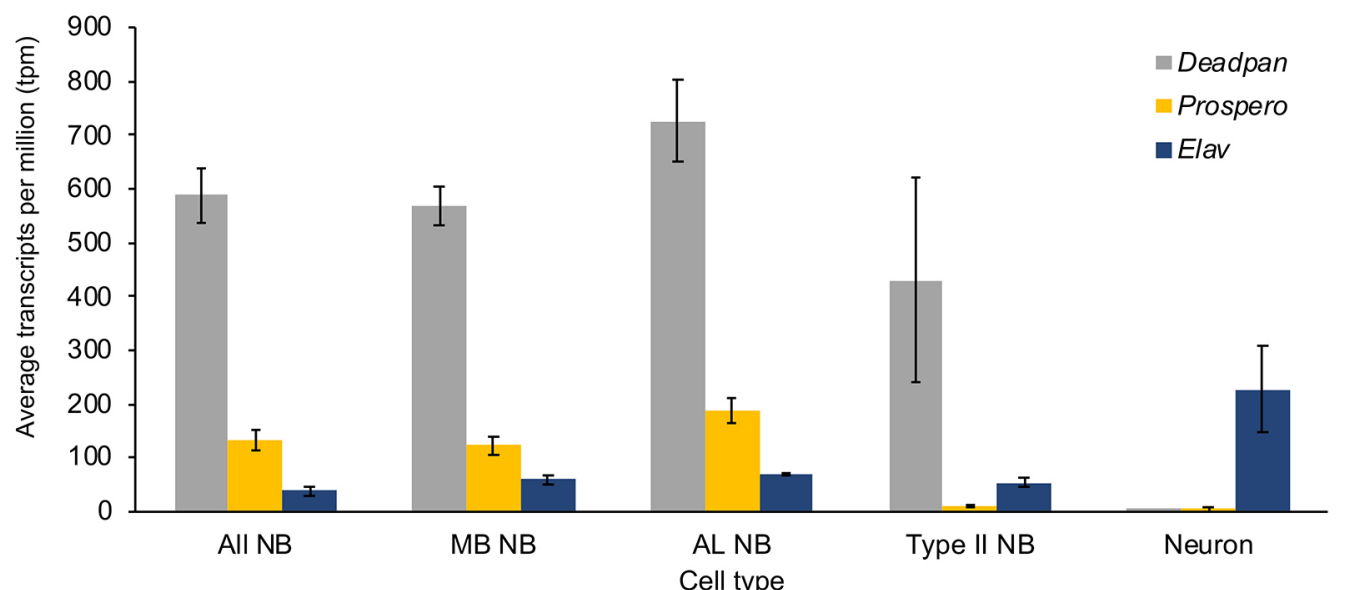

